IZA DP No. 9084

A Real-Effort Experiment on Gift Exchange with Temptation

Alexander K. Koch

Julia Nafziger

May 2015 


\title{
A Real-Effort Experiment on Gift Exchange with Temptation
}

\author{
Alexander K. Koch \\ Aarhus University \\ and IZA \\ Julia Nafziger \\ Aarhus University \\ Discussion Paper No. 9084 \\ May 2015 \\ IZA \\ P.O. Box 7240 \\ 53072 Bonn \\ Germany \\ Phone: +49-228-3894-0 \\ Fax: +49-228-3894-180 \\ E-mail: iza@iza.org
}

\begin{abstract}
Any opinions expressed here are those of the author(s) and not those of IZA. Research published in this series may include views on policy, but the institute itself takes no institutional policy positions. The IZA research network is committed to the IZA Guiding Principles of Research Integrity.

The Institute for the Study of Labor (IZA) in Bonn is a local and virtual international research center and a place of communication between science, politics and business. IZA is an independent nonprofit organization supported by Deutsche Post Foundation. The center is associated with the University of Bonn and offers a stimulating research environment through its international network, workshops and conferences, data service, project support, research visits and doctoral program. IZA engages in (i) original and internationally competitive research in all fields of labor economics, (ii) development of policy concepts, and (iii) dissemination of research results and concepts to the interested public.
\end{abstract}

IZA Discussion Papers often represent preliminary work and are circulated to encourage discussion. Citation of such a paper should account for its provisional character. A revised version may be available directly from the author. 


\section{ABSTRACT}

\section{A Real-Effort Experiment on Gift Exchange with Temptation *}

We conduct a real-effort experiment to test whether workers reciprocate generous wages by managers when workers are tempted to surf the internet. Further, we investigate how an active policy of restricting the usage of the internet affects the workers' motivation. We observe that the temptation of the internet hampers workers' willingness to reciprocate fair wages. Yet, when the manager makes an active choice not to deny internet access, workers perceive the "freedom from control" as a gift which they reciprocate with high effort. Whether the positive "freedom from control" aspect or the negative temptation aspect dominates depends on the worker's reciprocity: for highly reciprocal workers the control aspect dominates; for non-reciprocal workers the temptation aspect dominates.

JEL Classification: C91, D03, J33, M52

Keywords: gift exchange, temptation, hidden costs of control

Corresponding author:

Alexander K. Koch

Department of Economics and Business Economics

Aarhus University

Fuglesangsallee 4

8210 Aarhus V

Denmark

E-mail: akoch@econ.au.dk

\footnotetext{
* We thank Emma von Essen, Leonie Gerhards, Stefan Hirth, Marie Claire Villeval, Erik Wengström, as well as seminar participants in Aarhus, Berlin, Lund, and Vienna for helpful comments and discussions. Maria Skov Gregersen, Thomas Thoft Jensen, and Heidi Christina Thysen provided excellent research assistance. Part of the zTree code was taken from Abeler et al. (2011), and we would like to than the authors for sharing. Financial support from Aarhus Universitets Forskningsfond, AU IDEAS 2011, Grant number AUFF-E-201-FLS-1-17 and the Danish Council for Independent Research - Social Sciences (FSE) under grant 12-124835 is gratefully acknowledged.
} 


\section{Introduction}

Access to the internet distracts many people from their work, tempting them to read the news online, check on their social networks, or write private messages 11 Estimates abound of productivity losses due to such private online activities at the workplace $\mathrm{2}^{2}$ While most of these estimates have serious flaws, they do mirror companies' worries about their employees spending too much time online and being distracted by the Web. Consequently, many companies have strict policies about the private usage of the internet. Yet, other companies deliberately abstain from having such rules.$^{3}$ Davenport (2011) points out in a publication by the management consulting company McKinsey that "Knowledge workers typically enjoy the free-access approach [...] This positive feeling is probably useful for retention and job engagement." But at the same time it must be "assumed that [employees] have the discipline to avoid wasting time surfing the Web [...]." This hints at the advantages and disadvantages that an internet policy may have. While a restrictive policy removes a temptation that may distract employees from their work it also signals distrust by the employer, which may endanger job engagement. So what is the right approach?

The aim of this paper is to investigate in a lab experiment how the temptation of the internet and the internet policy of a firm affect the motivation of its workers. Importantly, the internet policy of a firm should not be seen in isolation from its wage policy. In our experiment, a manager and a worker interact in a gift-exchange game where the manager chooses what wage to pay the worker matched with him (from a menu with three possible wage levels). The profit of the manager depends on his own effort and the effort of the worker minus the wage paid to the worker. Effort is measured by a real effort task.

\footnotetext{
${ }^{1}$ According to MyJobGroup.co.uk around 6 percent of the British workforce spent over an hour per day on social media while at work. The average employee accesses his e-mail around 50 times per day and visits more than 40 web sites a day according to data from over 40,000 users of the "RescueTime" program, which tracks how much time people spend with a certain application on their computer.

${ }^{2}$ Just search for keyword combinations like productivity loss + facebook.

${ }^{3}$ For example, at the UK Department for Work and Pensions the private use of social networks is forbidden and the department took disciplinary action against 116 employees for using social networks during work time - 11 of these have been fired (Halliday 2013 in the Guardian). Their German counterpart ("Arbeitsministerium") in contrast sees no problem in their employees using social networks during work time as long as the employees meet their work obligations (SüddeutscheZeitung 2013).
} 
To study how the temptation of the internet affects effort, our experiment has two treatments where access to the internet is exogenously determined. In the NoInternet treatment, workers (and managers) by default do not have access to the internet. In the Internet treatment, everyone has access by default. A third treatment makes the internet policy a choice variable of the manager. In the Choice treatment, managers decide whether or not to grant internet access to the worker (in addition to deciding the wage level). Managers always have internet access in this treatment. In all treatments we additionally elicit measures for how trusting and reciprocal participants are using a trust game.

In his seminal paper, Akerlof (1982) argued that there is a positive relation between effort and wage levels because workers see a generous wage as a "gift" and they reciprocate by providing more than "normal" effort. This has been found to hold true in numerous lab experiments. Our Internet and NoInternet treatments allow us to study whether such gift exchange occurs also when workers are tempted by access to the internet.

We observe that workers provide little effort when the employer only offers a low wage - no matter whether the internet is on or off by default. Yet, when receiving a high wage it matters whether the internet is on or off: Workers without internet access provide more effort than those with access. Intuitively, while workers want to reciprocate a generous wage by working hard, the temptation to surf the internet seems to be in conflict with this motive. In fact, workers who receive a high wage and are tempted by access to the internet put in no more effort on average than those workers who receive a low wage and have no access to the internet. This result is consistent with the interpretation that temptation can completely crowd out reciprocal motives.

Our Choice treatment allows us to investigate how a manager's policy on internet usage affects a worker's motivation. On the one hand, restricting access to the internet takes away the temptation - i.e., offers a commitment device to workers not to get distracted - and thereby should increase effort. But, on the other hand, such a policy signals distrust by the manager and might crowd out the motivation of the worker to do a good job: A worker who perceives the policy of restricting internet access as excessive control will think of it as an unkind act of the manager and might reciprocate with lower effort. That is, there might be "hidden costs of control" (cf. Falk and Kosfeld 2006).

We observe that workers who receive a high wage provide more effort when the internet 
is turned-on by the choice of the manager rather than on by default. As working conditions are otherwise equal in these two settings, this result indicates that a policy of actively allowing internet access is perceived by the workers as a kind act and that it triggers positive reciprocity. Similarly, we find that effort tends to be lower when the internet is turned-off by the choice of the manager rather than off by default (though this effect is not significant for a high wage), indicating that a policy of denying internet access is perceived as unkind because it signals distrust.

When comparing efforts across the different policies of the manager in the Choice treatment (to allow or to deny internet access), not only these kindness effects play a role, but also the commitment effect identified above. We observe that the two effects are of similar magnitude: average efforts do not differ significantly depending on whether the manager actively turns the internet on or off (for both low and high wages). That is, overall, we do not find "hidden costs of control".

Taking into account the level of reciprocity of a worker allows us to further disentangle these effects. Reciprocity is measured by the amount returned in a trust game that participants play after the gift-exchange game. For a high wage, we observe that low-reciprocity workers provide less effort when granted internet access than when it is denied, and we find no significant kindness effects. That is, low-reciprocity workers do not appear to perceive "freedom from control" as a gift by the manager that should be reciprocated. Hence a policy of allowing internet access does not positively affect their motivation, but it does tempt them to surf the internet instead of working. High-reciprocity workers, in contrast, perceive "freedom from control" as a gift that should be reciprocated: they provide more effort when granted internet access by the manager than when it is denied.

Related literature. Our paper contributes to several literature strands. The first is the experimental literature on "hidden costs of control" initiated by Falk and Kosfeld (2006). All studies in this field consider abstract effort choices and control mechanisms. The effort of a worker is a number, where the effort cost increases with the number value. Control amounts to specifying a minimum number (interpreted as minimum effort requirement). We contribute to this literature by considering real effort and a control mechanism that is more prevalent in practice. In contrast to an (often infeasible) binding minimum effort 
requirement, restricting internet access is a 'soft' control mechanism that does not affect effort per se $4^{4}$ Further, by linking a measure of reciprocity to actual behavior, our experiment contributes to the mixed evidence on the emergence of "hidden costs of control". While Falk and Kosfeld (2006) find such costs of control, replications of their experiment typically do not find them or only in a subpopulation (Hagemann 2007, Schnedler and Vadovic 2011, Ziegelmeyer et al. 2012). Our results may help understand the divergence of findings. On the one hand, we provide clear evidence that low-reciprocity workers do not mind being controlled (they work more when they are controlled). On the other hand, we find that high-reciprocity workers do react positively to "freedom from control". Whether hidden costs of control arise for the overall population hence depends on the share of reciprocal versus non-reciprocal workers.

Second, we contribute to the literature that studies gift exchange in the lab and in the field. Numerous lab experiments test and confirm Akerlof's (1982) gift-exchange hypothesis in various settings (e.g., Fehr et al. 1993, 1998, Charness 2000, Brandts and Charness 2004, Maximiano et al. 2007). In contrast, most results from field experiments do not support the gift-exchange hypothesis (e.g., Gneezy and List 2006, Bellemare et al. 2009, HennigSchmidt et al. 2010, Kube et al. 2012, 2013). Our findings shed further light on these different results, by indicating that temptations (that are most likely present in the field, but not in the typical lab experiment) can very quickly erode reciprocal motives that are initially present. The study by Cohn et al. (2013) is, up to now, the only one that finds gift exchange in the field. They observe that it is those workers who feel underpaid at the base wage who increase their effort in response to a wage increase - a feature that will be important for the design of our experiment. Further, they observe that only individuals who show reciprocal behavior in a choice task are reciprocal in the field. In line with this, our results suggest that low-reciprocal subjects quickly succumb to the temptation to surf the Web, while high-reciprocal subjects seem more immune towards such temptations.

There are a few studies that test the gift-exchange hypothesis in the lab with real effort tasks (e.g., Brüggen and Strobel 2007, Hennig-Schmidt et al. 2010, Englmaier and Leider

\footnotetext{
${ }^{4}$ Other examples of such 'soft' control mechanisms are policies that regulate when and how often employees may take breaks, usage of private mobile phones at work, whether employees may work from home and whether and how working hours are monitored.
} 
2010). Our main contribution to this literature strand is to introduce one tempting feature from real-world work places - internet access - to examine how temptation influences workers' willingness to reciprocate high wages and how managers' control policies influence gift exchange. The internet also adds real opportunity costs to the task that make shirking more meaningful to workers. In most of the existing real-effort studies "shirking" meant staring out of the window or just working more slowly.

Lastly, we contribute to the small experimental literature that studies how participants are tempted by the internet. None of these examine gift exchange and they all address a different research question than ours. Houser et al. (2010) ask whether the internet tempts participants to be less productive, and they study whether and when participants take up commitment devices such as removing for themselves the access to the internet. Corgnet et al. (2011) observe that peer monitoring mitigates shirking under team incentives when participants are tempted to surf the internet.

\section{Experimental Design and Procedures}

Our computerized experiment (zTree, Fischbacher 2007) has five stages. Participants are informed about the number of stages at the beginning of the experiment and that the instructions for each stage are distributed before each stage $5^{5}$ In stage 1 , participants spend 10 minutes counting the number of zeros in a series of tables with 150 entries each. This task is boring and pointless and it does not require any prior knowledge (Abeler et al. 2011). Further, performance in this task is easily measurable. For each table in which a participant counts the number of zeros correctly he receives 1.5 Danish kroners (kr.), approximately 0.26 USD. The aim of this stage is to get a productivity measure, and henceforth we will refer to the number of correctly counted tables in this stage as the productivity of a participant. To make guessing the answer difficult the tables randomly vary in their level of difficulty $\left.\right|^{6}$ There is no access to the internet in this stage.

In stage 2, participants play a gift-exchange game with real effort. They are randomly assigned to the role of a worker or a manager and matched in worker-manager pairs. Both

\footnotetext{
${ }^{5}$ Instructions are reproduced in the appendix.

${ }^{6}$ The probability that a zero was drawn for a table-cell was either $0.3,0.5$, or 0.7 .
} 
workers and managers face the task of counting the number of zeros in a series of tables for 62 minutes. We refer to the number of correctly counted tables in this stage as the effort of a participant. The 62 minutes are divided into five ten-minute blocks with a threeminute break in between two blocks. We implement these breaks so as to give participants the opportunity to recover from the possibly resource-depleting task (for the importance of taking work breaks see, e.g., Trougakos and Hideg 2009). A participant is informed after each table whether he counted it correctly or not and the screen shows the total number of correctly counted tables. A manager gets $1.5 \mathrm{kr}$. for each table in which he counts the number of zeros correctly, and $1.5 \mathrm{kr}$. for each table in which the worker matched with him counts the number of zeros correctly. In addition, the manager gets a fixed payment of 150 kr.. The manager offers the worker a wage, choosing between the wage levels 100, 150, and $200 \mathrm{kr}$. . The worker is informed about this wage before he starts counting.

Our three treatments differ with respect to access to the internet during stage 2. In treatment NoInternet, the internet is off for all participants whereas it is on during treatment Internet. In treatment Choice, the manager can decide whether or not to grant the worker access to the internet and the worker is informed about this decision along with the wage before starting to work. Managers always have internet access in this treatment.

In all treatments, we use a split-screen design. The right side of the screen shows either a browser with the Google search page open (treatments Choice and Internet) or it is blank (treatment NoInternet). The browser is programmed so that participants cannot close or cover it and thereby change the treatment themselves. The left side of the screen shows the computerized experiment. Windows cannot be resized. In the treatments with internet access, we emphasize that we do not store the specific web pages a participant visits and encourage participants to delete their browsing history at the end of the experiment with the help of a button at the top of the screen. The tables are copy-protected so that participants cannot use some (online) program (like Excel) to do the counting for them..$^{7}$ Throughout all treatments we prevent possible peer effects from the clicking sounds that other participants make by playing random sequences of clicking sounds over speakers that make it impossible to notice what others are doing.

\footnotetext{
${ }^{7}$ To prevent other programs on the computer from being opened, the task bar is hidden and common keyboard short-cuts for reaching the desktop or other windows are deactivated.
} 
In the remaining stages, we elicit a number of control variables. In stage 3 , we elicit the belief of a participant about the effort and productivity of the participant with whom he is matched, paying an additional $10 \mathrm{kr}$. if the belief matches actual counted tables +/1. In stage 4, participants play a trust game. Here the sender can send 0, 10, 20, or 30 $\mathrm{kr}$. to the receiver. Any amount sent is tripled, and the receiver can send back any amount up to the total amount received. We use the so-called strategy-elicitation method with role uncertainty. Each participant has to make the choice as a sender and receiver. Afterwards he is randomly assigned one of these roles and randomly matched with another participant in the other role (this ensures that participants do not expect to be matched with the same person as in stage 2). Payoffs are calculated according to the relevant decisions of the two matched participants. We refer to the amount that a sender sends as a participant's trust, and to the average return rate as a participant's reciprocity. In stage 5, participants answer some survey questions, including background information (grades, nationality, study area), their risk preferences and some psychological scales.

The experiment was conducted at the Cognition and Behavior Lab of Aarhus University in Fall 2013 and Spring 2014. Participants were students from Aarhus University from various fields of study. In total, 300 participants participated in 33 sessions. Of these we need to exclude one worker and six managers from our analysis ${ }^{10}$ An experimental session lasted

\footnotetext{
${ }^{8}$ As all these variables are measured after the main stage, there might be some confounding effects if the choices of the main stage influenced choices thereafter. Note that this should not be an issue with the variables measuring preferences (the trust game, the risk questions, and the psychological scales), as one would expect preferences to be stable throughout the experiment (see also footnote 19). But some care should be taken with the belief variables and we hence check that our later results are robust to excluding them.

${ }^{9}$ Grades, risk aversion, the psychological scales all have no significant effects in the regressions - neither on workers, nor on managers. We thus will neither discuss nor include these variables in the following results.

${ }^{10}$ The worker, who had a wage of 100 and was denied internet access by the manager, left seven minutes into the main work part of the experiment and we hence do not have the full set of control variables (the return rate in the trust game and the belief about manager effort are missing). In one session, participants accidentally were given the instructions for the Choice treatment while the internet was on by default. For workers it looked as if managers granted them internet access and their behavior hence is unaffected. While no manager participant asked any question or commented on the issue, their behavior may have been affected and we exclude them from the analysis.
} 
around 2 hours. Average pre-tax earnings were $267 \mathrm{kr}$., approximately 47 USD. Payments were made directly into the participants' bank accounts 2-6 weeks after the experiment.11 Participants were asked to switch off and leave in an adjacent room any mobile phone they had, and they were instructed not to talk to each other during the sessions.

\section{Predictions}

In the following, we describe the predicted effects intuitively. A theoretical model can be found in the appendix. It is similar to the model of Kube, Maréchal and Puppe (2013) and based on a simplified version of the reciprocity model by Cox et al. (2007). We will omit currency units (all payoffs are in kr.).

Standard theory predicts that workers do not provide any effort. Yet, if workers have reciprocal preferences, they 'repay' a gift from the manager (a generous wage) by providing effort above the minimum. As discussed before, such behavior has been observed in numerous lab experiments, but rarely in field experiments. One reason for the lacking gift exchange in field experiments might be that the base wage already is perceived as generous. Increases beyond this base wage then may have no impact on effort (cf. Cohn et al. 2013). In addition, other real-effort experiments with wage setting, like Englmaier and Leider (2010), suffered from managers not choosing to pay a generous wage. We have chosen the frame of the wages in our experiment to avoid such reasons for lacking gift exchange. First, the manager receives an extra endowment of 150 so that paying a wage of 100 could appear like the manager is keeping 50 to himself that are actually meant for the worker. Second, according to our calibrations based on Abeler et al. (2011), the manager's and worker's payoff should be roughly equal if they put in average effort and the manager pays the worker 150, i.e.,

\footnotetext{
${ }^{11}$ This was done via the Danish payment system through which public bodies and companies can send money to a person using their social security number. This procedure was explained in detail to participants (see the extract from the consent form in the appendix). It is required by Aarhus University for tax reasons and perceived as normal by Danish citizens. In case participants had any doubts or questions later on about the payment procedure, we handed out a business card with our contact information. For this experiment the payment procedure also had two desired side-effects: (i) effort costs were immediate while benefits were delayed - as is common in self-control problems; (ii) it mirrors the wage payment procedure in Danish firms.
} 
spends the entire extra endowment on the wage. ${ }^{12}$ Third, the 100 wage is lower than the typical wage in a student job in Denmark.

We therefore expect that participants will perceive the wage of 100 as stingy or 'unfair' and the wage of 150 as generous or 'fair', and we predict that workers provide more effort when receiving a wage of 150 (because they feel treated kindly by the manager) than when receiving a wage of 100 (because they feel treated unkindly by the manager).13 We do not have a clear-cut hypothesis on the effort response to a wage of 200 compared to 150 . Models of distributional fairness (Fehr and Schmidt 1999) or reciprocity (Dufwenberg and Kirchsteiger 2004) predict that effort with a wage of 200 is higher than with a wage of 150 , while Akerlof and Yellen (1990) and Cohn, Fehr and Goette (2013) suggest that increases above the "base" or "fair" wage should not yield any significant increases in effort.14

Prediction 1 (Gift exchange) Workers provide more effort with a wage of 150 than with a wage of 100. With a wage of 200 workers work weakly more than with a wage of 150.

Access to the internet tempts individuals (Houser et al. 2010) and neuroscientific evidence suggests that multitasking, such as checking emails while writing a report, makes people less productive (cf. Dux et al. 2006). In our formal model in the appendix, we capture such effects by assuming that access to the internet increases the opportunity costs of working. Because of higher opportunity costs, the effort of workers should be lower when workers by default have access to the internet (treatment Internet) than when they do not have such access (treatment NoInternet).

\footnotetext{
${ }^{12}$ In Abeler et al. (2011), participants needed on average $53 \mathrm{sec}$ for counting the number of zeros correctly in a table. Thus, we predicted that our participants could correctly count on average 56 tables (3000 sec $\times 1 / 53$ tables/sec $)$. With these averages, the manager would earn $168 \mathrm{kr} .(2 \times 56 \times 1.5)$ if the worker does not shirk. From the first stage in our experiment, participants should have a rough feeling about the expected efforts in the second stage.

${ }^{13}$ Of course, if workers already reached their productivity limit with a wage of 100 (and no internet access) we would observe no wage or treatment effects. The data however indicate that workers are not at their limit (see footnote 18 ).

${ }^{14}$ When designing the experiment we included the wage of 200 for framing reasons to obtain a symmetric wage menu where the fair 150 wage is the intermediate choice rather than the highest wage: According to the compromise effect of Simonson (1989), adding an extreme option to a pairwise choice induces people to choose the middle option. In our case this helps ensure that enough managers choose the wage of 150 .
} 
Further, we predict that there are interaction effects between internet access and the wage. Let us first consider exogenous access to the internet (treatment Internet vs. NoInternet). When receiving a wage of 100, most workers should feel treated unkindly and a substantial fraction should respond to this by providing low or zero effort. This effect should be present no matter whether the internet is on or off. As in other gift-exchange experiments, we expect some workers to provide more than minimal effort even when receiving a low wage. For them having access to the internet should make shirking more interesting (surfing the internet is more pleasurable than staring out of the window), which hence should decrease their effort. Overall, we therefore predict a negative, but small effect of the internet on effort at a wage of 100. When receiving a wage of 150 (or 200), workers should feel treated kindly and a substantial fraction will want to reciprocate by providing substantial effort. But, at the same time, they are tempted to surf the internet. Thus, we predict a strong negative effect of internet access on effort if a worker receives a wage of 150 (or 200). That is, effort in treatment Internet should be lower than in treatment NoInternet.

Mirroring real workplaces, managers set wages in our experiment. However, because wages are endogenous, the interaction effects between wages and internet access potentially are not straightforward to interpret. The comparisons of efforts between treatments Internet and NoInternet for a particular wage level would not reflect the causal effects of the internet on effort if - when the internet is on by default - a wage of 150 (or 200) was perceived as unkind, while - when the internet is off by default - the same wage was perceived as kind 15 In the appendix, we consider models of reciprocity and difference aversion (Dufwenberg and Kirchsteiger 2004, Cox et al. 2008, Fehr and Schmidt 1999) and show that none of these

\footnotetext{
${ }^{15}$ More formally, following the notation of Angrist and Pischke (2008), let the potential effort of participant $i$ under treatment $\tau$ at wage $w$ be $e_{i, \tau, w}$, where $\tau=I$ denotes the Internet treatment and $\tau=N I$ denotes the NoInternet treatment. Denote the actually observed effort by $e_{i}=e_{i, N I, w}+\left(e_{i, I, w}-e_{i, N I, w}\right) \mathcal{I}_{\tau=I}$, where $\mathcal{I}$ is the indicator function. For the comparisons between treatments Internet and NoInternet for a particular wage level we then have

$$
E\left[e_{i} \mid w, I\right]-E\left[e_{i} \mid w, N I\right]=E\left[e_{i, I, w}-e_{i, N I, w} \mid w, I\right]+\underbrace{E\left[e_{i, N I, w} \mid w, I\right]-E\left[e_{i, N I, w} \mid w, N I\right]}_{\text {Bias }} .
$$

The worrying case (i.e., where the bias works in favor of our hypothesis) is when the bias is negative. None of the models we consider in the appendix predict this to be the case. That is, if at all, we underestimate the true effects, obtaining lower bounds on the size of the causal effects.
} 
models predicts this effect. Thus, the drawbacks of the endogenous wage variation are likely to be minimal. The alternative route of making the wage variation (quasi) exogenous, but at the same time letting managers choose wages, has serious drawbacks as it either requires a very complicated design that makes the experiment both unrealistic and unnatural to participants, or it requires withholding information to an extent that is deceptive.

Prediction 2 (Exogenous access to internet) Workers provide less effort when the internet is on (treatment Internet) than when it is off (treatment NoInternet) by default. This effect is driven by the effort response at a wage of 150 (or 200). Here workers provide strictly less effort when the internet is on than when it is off. At a wage of 100, workers provide little effort no matter whether the internet is on or off.

We now turn to comparisons across treatments Internet and NoInternet with the corresponding choices of the manager in the Choice treatment. Comparing efforts when internet is on by default (Internet) and when it is turned-on by the manager's choice (Choice-Internet) reflects the 'kindness effect' of the manager's choice ${ }^{16}$ Switching the internet on - i.e., actively giving "freedom from control" - and paying a fair wage should be perceived by workers as a gift and thereby as a kinder policy than paying this wage when the internet is on by default. Similarly, the comparisons across conditions NoInternet and Choice-NoInternet reflect the effect that a manager's 'unkind' choice to restrict internet access has on effort. Thus, we predict that if the manager pays a wage of 150 (or 200), effort should be higher (lower) if the internet is on (off) by choice of the manager rather than by default.

\footnotetext{
${ }^{16}$ Comparing average efforts across the two treatments Internet $(I)$ and Choice-Internet $(C I)$ gives:

$$
E\left[e_{i} \mid I, w\right]-E\left[e_{i} \mid C I, w\right]=\underbrace{E\left[e_{i, I, w} \mid I, w\right]-E\left[e_{i, C I, w} \mid I, w\right]}_{A}+\underbrace{E\left[e_{i, C I, w} \mid I, w\right]-E\left[e_{i, C I, w} \mid C I, w\right]}_{B} .
$$

Term A should be zero because the working environment is the same in $C I$ and $I$ and workers hold the same belief about the manager's choice. Term B captures the impact of how kind workers think that paying a wage of, say, 150 and the manager granting internet is relative to the setting with exogenously provided internet access.
} 
Prediction 3 (Exogenous vs. endogenous internet access) At a wage of 150 (or 200), effort is higher if the internet is turned-on by choice of the manager (treatment ChoiceInternet) rather than by default (treatment Internet). At a wage of 150 (or 200), effort is lower if the internet is turned-off by choice of the manager (treatment Choice-NoInternet) rather than by default (treatment NoInternet). These differences reflect the (un)kindness effect of the manager (dis)allowing access to the internet. At a wage of 100, workers provide little effort no matter whether there is internet access by default or by choice of the manager.

The manager's decision in the Choice treatment whether to grant or deny internet access has two opposing effects on effort.17 First, the comparisons across different internet policies of the manager for a given wage capture a direct, 'commitment effect' of the internet on effort: Turning off the internet serves as a commitment device for workers not to get distracted by the internet and facilitates providing effort. Second, the comparisons also capture an indirect, counterbalancing, kindness effect. If workers like "freedom from control", a policy of paying a wage of 150 and turning the internet on is perceived as kinder than a policy of paying a wage of 150 and turning the internet off. The overall effect depends on the strength of the commitment and kindness effects and we expect that participants are heterogeneous with respect to this.

For participants who are not very reciprocal (in our experiment this is measured by the receiver response in the trust game), the commitment effect should dominate the kindness effect because these participants do not care much about the kindness of the manager's internet-wage policy. We hence expect that they should work more when the internet is turned-off than when it is turned-on. For highly reciprocal participants who care strongly about the kindness of the internet-wage policy of the manager, the kindness effect should

${ }^{17}$ The overall effect of switching the internet on (Choice-Internet, CI) vs. switching it off (ChoiceNoInternet, $C N I$ ) is captured by

$$
E\left[e_{i} \mid w, C I\right]-E\left[e_{i} \mid w, C N I\right]=\underbrace{E\left[e_{i, C I, w}-e_{i, C N I, w} \mid w, C I\right]}_{\text {Direct effect }}+\underbrace{E\left[e_{i, C N I, w} \mid w, C I\right]-E\left[e_{i, C N I, w} \mid w, C N I\right]}_{\text {Indirect effect }} .
$$

The indirect effect captures the impact of the worker's belief about the kindness of the manager's policy. It can be understood as asking (hypothetically) how kind a wage of, say, 150 is when the manager wanted to turn the internet off relative to when the manager wanted to turn the internet on, but some fault not under his control disabled the internet. 
dominate the commitment effect. That is, we expect that highly reciprocal participants work less when the internet is turned-off than when it is turned-on. In particular, these effects should be stronger for the fair wage of 150 (or 200) than for the unfair wage of 100, where participants are expected to provide little effort anyway.

Prediction 4 (Endogenous internet access) The manager's choice whether to deny internet access (Choice-NoInternet) or grant internet access (Choice-Internet) has two opposing effects on effort - the commitment effect and the kindness effect. The strength of each effect depends on the type of worker. At a wage of 150 (or 200),

(a) effort of low-reciprocity workers is higher when the internet is turned-off than when it is turned-on (the commitment effect dominates).

(b) effort of high-reciprocity workers is lower when the internet is turned-off than when it is turned-on (the kindness effect dominates).

At a wage of 100, workers provide little effort no matter whether the manager turns the internet on or off.

Our final set of predictions relates to the behavior of the managers. We predict that managers provide more effort than workers because their incentives to work from the piece rate should be stronger than the incentives to work for a worker which stem from the reciprocal concerns the worker has towards the manager. Managers are also affected by the temptation of the internet, and hence should provide less effort when the internet is on than when it is off. Anticipating gift exchange by the workers, managers may offer a wage of 150 instead of 100. But if, as we predict, workers feel already treated fairly with a wage of 150 , managers should not offer a wage of 200. Because internet access raises the opportunity cost of effort, managers should offer a lower wage if there is exogenous internet access than if there is no access. The more trusting a manager is, the more likely that he offers the fair wage 150 in all treatments and the less likely that he denies the worker access to the internet in the Choice treatment. 
Table 1: Summary statistics for productivity and effort

\begin{tabular}{|c|c|c|c|c|c|c|}
\hline Treatment & $\mathbf{N}^{a}$ & Productivity & Effort & $\mathbf{N}^{a}$ & Productivity & Effort \\
\hline & \multicolumn{3}{|c|}{ Workers } & \multicolumn{3}{|c|}{ Managers } \\
\hline \multirow[t]{2}{*}{ Internet } & 45 & $10.69^{* * *}$ & $44.87^{* * *}$ & 45 & $8.38^{* * *}$ & $59.16^{* * *}$ \\
\hline & & $(3.78)$ & $(26.68)$ & & $(3.70)$ & $(21.00)$ \\
\hline \multirow[t]{2}{*}{ NoInternet } & 17 & 10.47 & 52.18 & 17 & 9.29 & 55.59 \\
\hline & & $(3.62)$ & $(21.61)$ & & $(3.48)$ & $(20.54)$ \\
\hline \multirow[t]{2}{*}{ Choice-Internet $^{b}$} & 53 & 9.79 & $43.81^{* * *}$ & 82 & 10.27 & $65.17^{* * *}$ \\
\hline & & $(3.53)$ & $(26.91)$ & & $(3.93)$ & $(20.21)$ \\
\hline \multirow[t]{2}{*}{ Choice-NoInternet ${ }^{b}$} & 34 & 9.29 & 39.88 & - & - & - \\
\hline & & $(3.41)$ & $(26.06)$ & & & \\
\hline
\end{tabular}

Notes: Averages (standard deviation). ${ }^{a}$ One worker and six manager observations had to be excluded (see footnote 10. ${ }^{b}$ Managers always have internet access in treatment Choice. One-sided t-tests, workers' vs. managers' effort: ${ }^{* * *} p<0.01$ (for Choice only those workers with internet access are comparable).

\section{Prediction 5 (Managers' behavior)}

(a) Managers provide more effort than workers.

(b) Managers provide less effort when the internet is on (treatments Internet and Choice) than when it is off (treatment NoInternet).

(c) Wage offers of 200 are rare.

(d) Average wages are lower when the internet is on by default rather than off by default.

(e) The higher the manager's trust, the more likely that he pays a high wage (in all treatments) and the more likely that he grants internet access (in treatment Choice).

\section{Results}

\subsection{Impact of the internet and wages on effort}

Table1 provides summary statistics of workers' and managers' effort and productivity. Workers and managers are similarly productive (tables counted during the first 10 minutes of the experiment with individual incentives) in the overall sample (t-test, $p=0.29$, two-sided) 
Table 2: Impact of internet access on effort

\begin{tabular}{|c|c|c|c|c|c|c|}
\hline \multirow[t]{2}{*}{ Variable } & \multicolumn{3}{|c|}{ OLS } & \multicolumn{3}{|c|}{$\begin{array}{c}\text { Negative binomial regression } \\
\text { (marginal effects) }\end{array}$} \\
\hline & All & Workers & Managers & All & Workers & Managers \\
\hline \multirow[t]{2}{*}{ Productivity } & $3.29^{* * *}$ & $2.53^{* * *}$ & $4.23^{* * *}$ & $3.20^{* * *}$ & $2.50^{* * *}$ & $4.07^{* * *}$ \\
\hline & $(0.31)$ & $(0.55)$ & $(0.24)$ & $(0.25)$ & $(0.48)$ & $(0.29)$ \\
\hline \multirow[t]{2}{*}{ Any internet ${ }^{a}$} & -0.66 & -7.75 & $6.16^{*}$ & -0.31 & -6.67 & 6.45 \\
\hline & $(1.93)$ & $(5.21)$ & $(3.63)$ & $(2.21)$ & $(4.63)$ & $(4.57)$ \\
\hline \multirow[t]{2}{*}{ Constant } & $21.37^{* * *}$ & $25.64^{* * *}$ & $16.28^{* * *}$ & & & \\
\hline & $(3.51)$ & $(7.51)$ & $(4.72)$ & & & \\
\hline $\mathrm{R}^{2}$ & 0.25 & 0.13 & 0.64 & & & \\
\hline $\mathrm{N}^{b}$ & 293 & 149 & 144 & 293 & 149 & 144 \\
\hline
\end{tabular}

Notes: Dependent variable: effort. Standard errors clustered at session level are in parentheses. ${ }^{*} p<0.10$, ${ }^{* *} p<0.05,{ }^{* * *} p<0.01$. ${ }^{a}$ Any internet: a dichotomous variable equal to 1 in all conditions where the participants have internet access (Internet \& Choice for managers, and Internet \& Choice-Internet for workers) and 0 otherwise. ${ }^{b}$ One worker and six manager observations had to be excluded (see footnote 10.

and the individual treatments, except for Internet where managers are less productive than workers. Nevertheless, as hypothesized, workers work less than managers (prediction 5). The overall average of 44.19 tables for workers is significantly different from that of 62.16 tables for managers (t-test, $p<0.001$, one-sided) 18

To assess the impact of access to the internet on effort we turn to table 2, which shows OLS regressions of effort on productivity and availability of the internet. For robustness we include here also negative binomial regressions, which are well suited to modeling count data like ours and, unlike OLS regressions, account for the fact that effort is nonnegative. When considering all participants (workers and managers), we observe that internet access has no significant impact on effort. When considering managers and workers separately, we observe

\footnotetext{
${ }^{18}$ The comparisons of workers and managers indicates that workers are not at their productivity limit in the main part. Further evidence of this is that 82 percent of managers provide more effort than predicted if one takes five times their productivity measure as benchmark for the potential effort over the course of the main part, whereas only 50 percent of workers exceed the benchmark of $5 \times$ productivity.
} 
Table 3: Impact of wages on worker effort

\begin{tabular}{|c|c|c|c|c|}
\hline \multirow[t]{2}{*}{ Variable } & \multicolumn{2}{|c|}{ OLS } & \multicolumn{2}{|c|}{$\begin{array}{c}\text { Negative binomial regression } \\
\text { (marginal effects) }\end{array}$} \\
\hline & Effort & Effort & Effort & Effort \\
\hline \multirow[t]{2}{*}{ Productivity } & $2.86^{* * *}$ & $1.44^{* * *}$ & $2.86^{* * *}$ & $1.25^{* *}$ \\
\hline & $(0.55)$ & $(0.51)$ & $(0.48)$ & $(0.59)$ \\
\hline \multirow[t]{2}{*}{ Reciprocity $^{a}$} & & $19.71^{* * *}$ & & $14.01^{* *}$ \\
\hline & & $(7.01)$ & & $(6.51)$ \\
\hline \multirow[t]{2}{*}{ Belief about manager's effort } & & $0.51^{* * *}$ & & $0.51^{* * *}$ \\
\hline & & $(0.10)$ & & $(0.10)$ \\
\hline \multirow[t]{2}{*}{ Wage $=100^{b}$} & $-21.43^{* * *}$ & $-19.30^{* * *}$ & $-22.58^{* * *}$ & $-19.85^{* * *}$ \\
\hline & $(3.97)$ & $(3.68)$ & $(4.59)$ & $(4.06)$ \\
\hline Wage $=150$ & & mitted cat & & \\
\hline \multirow[t]{2}{*}{ Wage $=200$} & $7.35^{*}$ & $7.59^{* *}$ & 4.19 & 4.39 \\
\hline & $(4.32)$ & $(2.83)$ & $(3.45)$ & $(2.70)$ \\
\hline \multirow[t]{2}{*}{ Constant } & $24.60^{* * *}$ & 5.58 & & \\
\hline & $(5.48)$ & $(6.33)$ & & \\
\hline $\mathrm{R}^{2}$ & 0.31 & 0.49 & & \\
\hline $\mathrm{N}$ & 149 & 149 & 149 & 149 \\
\hline
\end{tabular}

Notes: Dependent variable: effort. Standard errors clustered at session level are in parentheses. ${ }^{*} p<0.10$, ${ }^{* *} p<0.05,{ }^{* * *} p<0.01 .{ }^{a}$ Reciprocity: average return rate in the trust game. ${ }^{b} \mathrm{~A}$ dichotomous variable $=1$ if the worker is in the wage category and 0 otherwise.

in the OLS regressions a significant positive effect for the managers that counterbalances an insignificant negative effect for the workers. It appears that the individual incentives the managers face are strong enough to sidestep the temptation of the internet. However, in contrast to our hypothesis (prediction 5), managers if at all work harder (the effect is not robust in the negative binomial regressions) when they have access to the internet and we can only speculate why this is the case. For example, it may be due to the different nature of the work breaks. According to Trougakos and Hideg (2009) two factors play a role for recovery during a break: low effort (such as sitting quietly, which participants have to do in the settings without internet access) and doing a preferred choice activity (surfing the Web 
is likely to fall into this category). The effort behavior of the manager is suggestive for the interpretation that breaks where participants can surf the Web are better at helping them to recover their productivity than where they stare at the wall. While we did not predict such a recovery effect, it makes any low effort response with internet access an even stronger indication of shirking.

For workers we observe that the internet has a negative impact on effort, yet the coefficient is not significant. Also the $R^{2}$ is very low - indicating that this model does not explain well worker's effort, but that we need to additionally consider wages and the interaction of wages and internet access. Starting with wages, the regressions in table 3 provide clear evidence for the gift-exchange hypothesis. Workers put in significantly more effort when receiving a wage of 150 than when receiving a wage of 100 (prediction 1) and the effect size is large: the higher wage shifts effort by 0.74 standard deviations. Further, we find in the OLS regressions that workers paid a wage of 200 work significantly more than those paid a wage of 150 (effect size 0.29 ), though this effect is not robust.

\subsection{Interaction between wage and internet access}

Table 4 provides summary statistics of how worker effort, wages, and internet access interact. Table 5 reports results from regressions with controls for a worker's productivity, reciprocity, and beliefs about the manager's effort.19 To generate table 5 we varied the omitted category in an effort regression so as to obtain a coefficient that captures the effect of interest. Specifically, we included dichotomous internet-wage interaction variables that are equal to one if a worker is in the respective condition for internet access and in the respective wage category and that are equal to zero otherwise. For example, the row Internet vs. NoInternet and the column wage $=100$ refers to an effort regression in which the omitted category is that the worker receives a wage of 100 and is in treatment NoInternet. The cell reports the coefficient on the interaction variable that is equal to one if the worker is in treatment

\footnotetext{
${ }^{19}$ Results are robust to dropping the beliefs variable, which - as mentioned in footnote 8 - potentially is a bad control. The trust game measures preferences, which one would expect to be stable. Indeed when regressing workers' reciprocity in the trust game on managers' choices (wage and a dummy for internet access in the Choice treatment) we find no spill-over effects. This rules out that, for example, a high wage induced a good mood and this increased measured reciprocity.
} 
Table 4: Summary statistics for the effort of workers by wage level

\begin{tabular}{|c|c|c|c|c|c|c|}
\hline \multirow{3}{*}{ Treatment } & \multicolumn{6}{|c|}{ Wage } \\
\hline & \multicolumn{2}{|r|}{100} & \multicolumn{2}{|r|}{150} & \multicolumn{2}{|r|}{200} \\
\hline & $\mathrm{N}$ & Effort $^{a}$ & $\mathrm{~N}$ & Effort & $\mathrm{N}$ & Effort \\
\hline \multirow[t]{2}{*}{ Internet } & 19 & 38.68 & 21 & $46.71^{*, \dagger}$ & 5 & 60.60 \\
\hline & & $(31.64)$ & & (21.13) & & $(24.21)$ \\
\hline \multirow[t]{2}{*}{ NoInternet } & 10 & $46.60^{\dagger \dagger}$ & 7 & $60.14^{*, \dagger}$ & 0 & \\
\hline & & $(21.80)$ & & $(20.16)$ & & \\
\hline \multirow[t]{2}{*}{ Choice-Internet } & 21 & 25.19 & 31 & $55.81^{\dagger}$ & 1 & 63.00 \\
\hline & & (20.03) & & $(24.16)$ & & $(0.00)$ \\
\hline \multirow[t]{2}{*}{ Choice-NoInternet } & 16 & $27.94^{\dagger \dagger}$ & 15 & $47.93^{\dagger}$ & 3 & 63.33 \\
\hline & & $(26.59)$ & & $(18.37)$ & & $(33.01)$ \\
\hline $\mathrm{N}$ & 66 & & 74 & & 9 & \\
\hline
\end{tabular}

Notes: ${ }^{a}$ Averages (standard deviation). One-sided t-tests: $\mathrm{H}_{0}$ : Internet $\geq$ NoInternet ${ }^{*} p<0.10$;

$\mathrm{H}_{0}:$ Internet $\geq$ Choice - Internet or $\mathrm{H}_{0}:$ Choice - NoInternet $\geq$ NoInternet ${ }^{\dagger} p<0.10,{ }^{\dagger \dagger} p<0.05$.

Internet and receives a wage of 100 and that is zero otherwise. With reference to the omitted category the coefficient hence captures the effort difference between treatments Internet and NoInternet for a wage of 100 . Note that we do not report results for the wage of 200 as very few managers choose this wage (see Table 4 ), in line with prediction 5.

When receiving a wage of 100, workers generally provide a somewhat low level of effort - no matter whether the internet is on or off. There is no significant difference between the average effort in treatments Internet and NoInternet. Similarly, there is no significant difference in average effort between workers who had internet access turned-off by the manager and those who had it turned-on. Intuitively, workers have negative reciprocal feelings when receiving a low wage. Thus, they provide little effort - no matter whether the internet is on or off by default. The exception seems to be if the manager deliberately denies internet access, which is associated with lower effort than if it is off by default.

When receiving a wage of 150 , it however matters whether the internet is on or off. Average effort is lower with default access than without and the effect size in the regression is large. Internet access lowers effort by 0.55 standard deviations. This is consistent with 
Table 5: Interaction effects between wages and internet

\begin{tabular}{|c|c|c|c|c|}
\hline \multirow[t]{2}{*}{$\begin{array}{l}\text { Variable }^{a} \\
\text { (Reference category) }\end{array}$} & \multicolumn{2}{|c|}{ OLS } & \multicolumn{2}{|c|}{$\begin{array}{c}\text { Negative binomial regression } \\
\text { (marginal effects) }\end{array}$} \\
\hline & Wage $=100$ & Wage $=150$ & Wage $=100$ & Wage $=150$ \\
\hline Internet & -0.53 & $-14.31^{*}$ & -2.44 & $-15.70^{*}$ \\
\hline (vs. NoInternet) & $(6.87)$ & $(6.22)$ & $(6.38)$ & $(8.31)$ \\
\hline Choice-NoInternet & $-12.86^{*}$ & -3.68 & $-14.92^{* *}$ & -2.82 \\
\hline (vs. NoInternet) & $(5.91)$ & $(6.45)$ & $(7.22)$ & $(7.04)$ \\
\hline Choice-Internet & -9.75 & $10.69^{*}$ & -11.83 & $9.03^{*}$ \\
\hline (vs. Internet) & $(6.69)$ & $(4.75)$ & $(8.55)$ & $(4.87)$ \\
\hline Choice-Internet & 2.58 & 0.06 & -0.08 & -1.86 \\
\hline (vs. Choice-NoInternet) & $(5.44)$ & $(4.00)$ & $(5.59)$ & $(4.86)$ \\
\hline $\mathrm{N}$ & 149 & 149 & 149 & 149 \\
\hline
\end{tabular}

Note: Coefficient from regression with dependent variable effort. Standard errors clustered at session level are in parentheses. ${ }^{*} p<0.10,{ }^{* *} p<0.05 .{ }^{a} \mathrm{~A}$ dichotomous treatment-wage interaction variable $=1$ if the worker is in the respective treatment and wage category and 0 otherwise. Each cell reports the regression coefficient from a separate regression with the omitted category given by "vs..." (additional controls: productivity, reciprocity, belief about manager's effort).

the hypothesis that workers want to reciprocate the fair wage of 150 - but then cannot resist the temptation of the internet and do not reciprocate to the desired extent (prediction 2). To what extent do such self-control problems crowd out reciprocal motives? The average effort of workers who by default have internet access and receive the fair wage of 150 is not significantly different from that of workers who by default have no internet access and receive the unfair wage of 100 (t-test, $p=0.99$, two-sided) 20 While we cannot identify a causal effect when we compare across (endogenous) wage levels and treatments, this result does suggest that temptation may completely crowd out reciprocal motives.

\footnotetext{
${ }^{20}$ Similarly, in a regression that controls for productivity, reciprocity, and beliefs about the manager's effort, we find a tiny and insignificant coefficient on the dummy for the 'unfair' wage 100 \& NoInternet (0.53, $\mathrm{p}$-value $=0.94)$ which suggests that effort is equal to the omitted category 'fair' wage 150 \& Internet. Later we will see that crowding out is not immediate but stems from workers giving in to the temptation of the internet in later work phases (see figure 4 ).
} 
Figure 1: Effects of internet access/policies on worker effort at wage 150

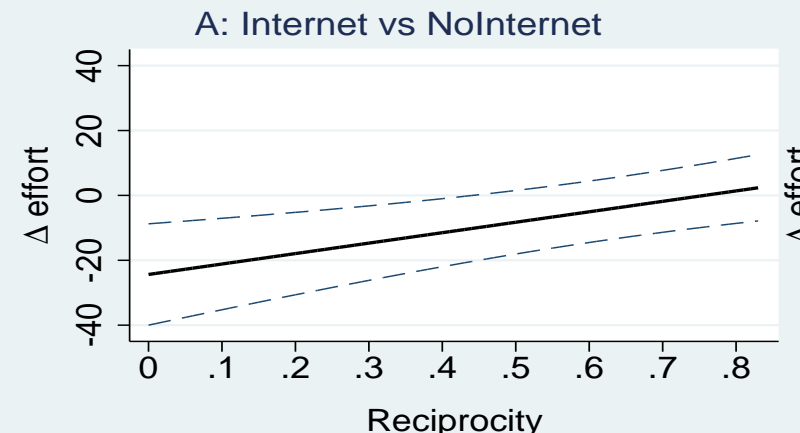

C: Choice-Internet vs Internet

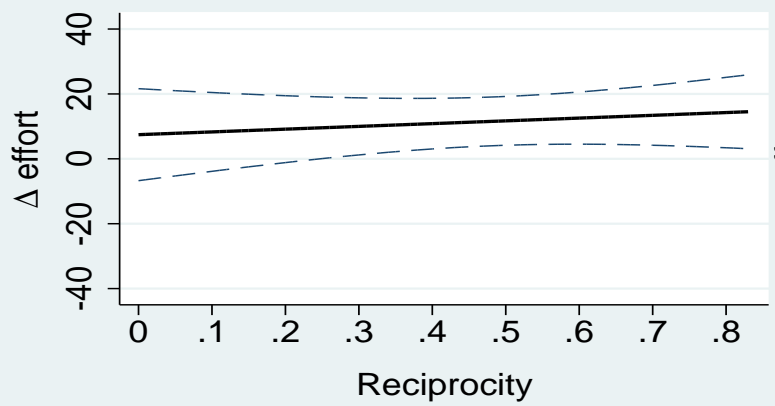

Notes: Predicted difference in effort (marginal effect at sample means of productivity and beliefs about the manager's effort) with 90-percent confidence interval. Reciprocity: average return rate in the trust game.

An active choice by the manager to grant access to the internet is associated with higher effort than if access is by default. Again the effect size is large (0.41 std.dev.). This observation is consistent with the hypothesized kindness effect, according to which workers view an active choice by the manager to grant internet access as kind and then reciprocate with higher effort (prediction 3). Correspondingly, an active choice by the manager to deny internet access is associated with lower effort than if access is off default. Note however that for this result the regression coefficient in table 5 is insignificant, though it has the right sign.

Turning to the effect of an active internet policy, at a wage of 150 there is no significant difference in effort across the choices to grant or deny internet access to the worker. Our hypothesis was that this comparison across conditions Choice-Internet and Choice NoInternet is driven both by the kindness effect of the manager giving the worker "freedom from control" and by the countervailing commitment effect that would be obtained when removing the temptation of the internet (prediction 4). Overall, we see that the kindness effect is not strong enough to counterbalance the commitment effect. 
Figure 1 shows that the worker's level of reciprocity drives the strength of the effects discussed above ${ }^{21}$ Each panel plots as a function of the worker's level of reciprocity the predicted difference in efforts caused by a particular internet-wage interaction effect, derived from OLS regressions with three-way internet-wage-reciprocity interactions. If the 90-percent confidence interval does not include zero for a given level of reciprocity, we speak of a significant internet-wage interaction effect at that level of reciprocity. To get a sense of the effect sizes, note that one standard deviation of worker effort corresponds to 26 tables counted.

We observe that the negative effort response in treatment Internet compared to treatment NoInternet for a wage of 150 is driven by low-reciprocity workers (figure 1 , panel A). For them the wage gift is not sufficiently motivating when they face the temptation of the internet, reflected by a significant drop in effort relative to the case with no internet access. The more reciprocal workers are, the more able they seem to be at resisting the temptation of the internet. Further, the results reveal that the overall insignificant effect of the manager's internet policy in the Choice treatment stems from heterogeneity in the responses of low- and high-reciprocity workers. High-reciprocity workers provide significantly more effort when the internet is turned-on than when it is turned-off (panel D). This is in line with our prediction 4 that for high-reciprocity workers the kindness effect dominates the commitment effect. Similarly, low-reciprocity workers respond with no difference or lower effort to internet access ${ }^{22}$ Considering the effect of an active choice to grant internet access relative to access by default, we find that high-reciprocity workers respond with higher effort to "freedom of

\footnotetext{
${ }^{21}$ Reciprocity is measured by the average return rate in the trust game. We used the strategy method with role uncertainty to elicit how much of $3 \times x$ participants would send back to a sender who invested $x>0$, with $x \in\{10,20,30\}$. The minimum observed return rate is zero and the maximum is 0.83 . The median return rate for workers is 0.33 , i.e. to return exactly the amount $x$ invested by the sender; 21 percent of workers return zero, 23 percent return a positive amount but less than $x$ (thus leaving the sender with a net loss), 13 percent return exactly $x$, and 43 percent return more than $x$.

${ }^{22}$ In the appendix, we show that the treatment differences Internet vs. NoInternet and Choice-Internet vs. Choice-NoInternet are robust to using different outcome measures. Figure 5 shows results with attempted tables (the sum of correctly and incorrectly counted tables) instead of effort as the outcome variable. Effort and attempted tables are of course correlated $(\rho=0.72, \mathrm{p}$-value $<0.01)$. Figure 7 uses as outcome variable whether a participant was inactive (does not make an entry in a table) for more than 2 minutes. Here we see that the predicted effects on the probability of inactivity are quite large.
} 
Figure 2: Relative effect of wage gift vs. internet gift

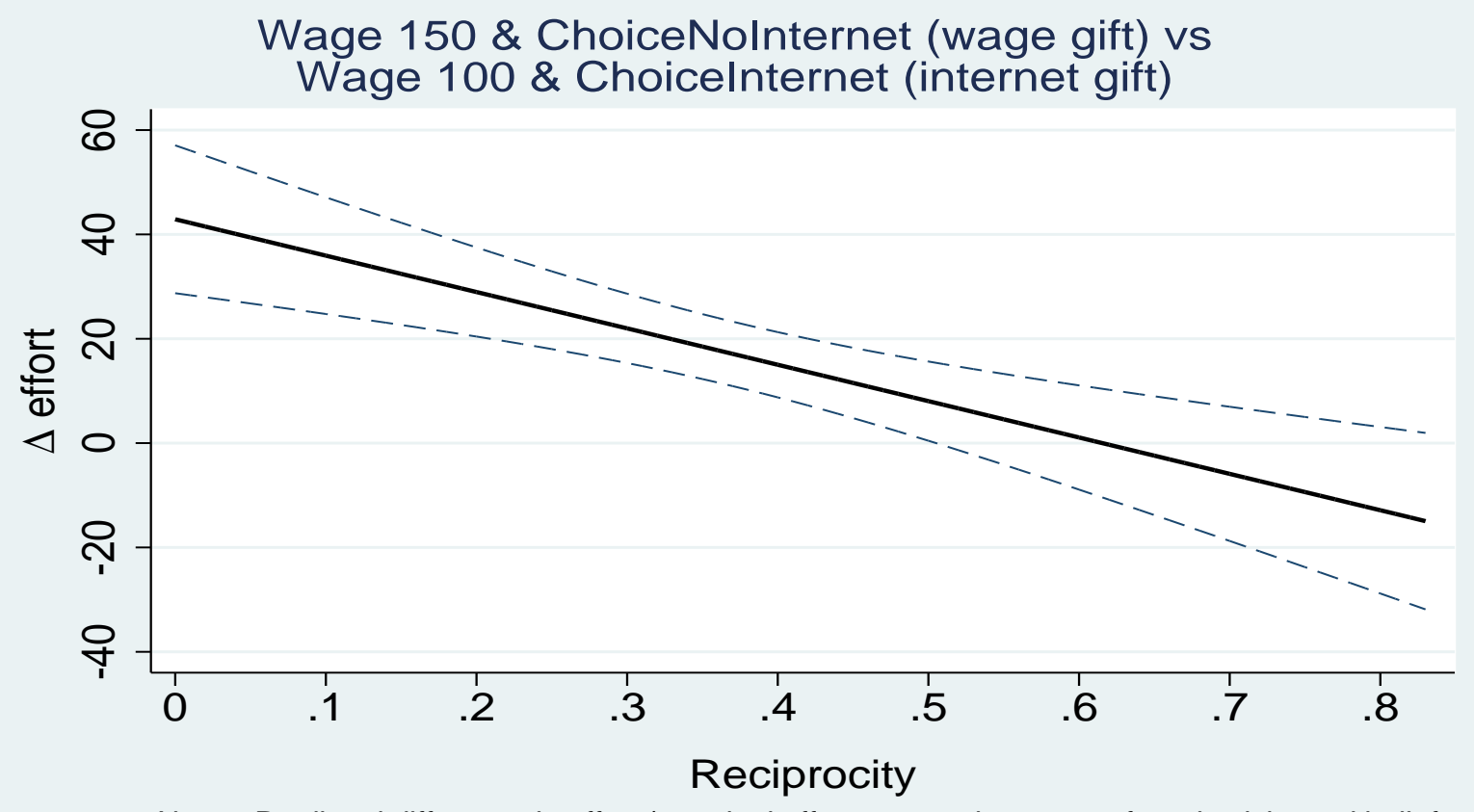

Notes: Predicted difference in effort (marginal effect at sample means of productivity and beliefs about the manager's effort) with 90-percent confidence interval. Reciprocity: average return rate in the trust game.

control" (panel C), in line with the hypothesized kindness effect (prediction 3). Similarly, we see a corresponding negative, albeit insignificant, unkindness effect (panel B).

Finally, we examine whether the wage gift or the internet gift is more important for worker effort. An effort regression is consistent with the interpretation that the wage gift is more important (as mentioned, we cannot identify causal effects when comparing across endogenous wage levels and internet policies). Effort with a wage of 150 when the internet is turned-off in the Choice treatment (wage gift only) is significantly larger than effort with a wage of 100 when the internet is turned-on (internet gift only) 23 Figure 2 reveals that this effect is driven by the low reciprocity workers. They work more with a wage of 150 and internet turned-off than with a wage of 100 and internet turned-on. As discussed before, for these workers internet access is more of a temptation to shirk than a gift to be reciprocated. In contrast, high-reciprocity workers put in similar (if not more) effort with a wage of 100 and internet turned-on as with a wage of 150 and internet turned-off. That is, for them the

\footnotetext{
${ }^{23}$ In an effort regression with omitted category wage 100 \& Choice-Internet the dummy variable wage 150
} \& Choice-NoInternet has a positive and significant coefficient (25.64***, std.err. 6.03). 
"freedom from control" seems to be at least as important as the actual wage.

\section{Effects over time}

Next we investigate how the temptation of the internet affects effort over time. Remember that there are five work phases, each lasting 10 minutes and separated by 3 minute breaks. Figure 3 shows that workers who by default do not have internet access respond to the fair wage of 150 with a permanently higher amount of average effort in each work phase than if they receive the unfair wage of 100 . Yet, when those workers who receive the fair wage of 150 also by default have access to the internet, their effort declines over time to the same level as for those who receive the unfair wage of 100 and have no internet access, see figure 4 (again with the caveat that we cannot identify causal effects when comparing across endogenous wage levels and treatments). This finding suggests that the temptation of the internet over time crowds out reciprocal motives that are initially present, and it provides a hint why we observe differences in gift exchange between the lab and the field. The setting with no internet access corresponds to the typical gift-exchange setting in the lab, whereas the setting with internet access more closely resembles a field setting where workers are exposed to more distractions and have more possibilities to do other things than work. It appears that such temptations can quickly erode reciprocal motives (in our experiment this happens over the course of an hour).

Similarly, we can examine how the effects vary over time for workers with different levels of reciprocity. Figure 5 shows for a wage of 150 the difference of the effort response in treatment Internet compared to treatment NoInternet. We observe that there is no significant difference between the two treatments in the first two work phases - neither for the low-reciprocity nor for the high-reciprocity workers. In later work phases, the low-reciprocity workers provide less effort in treatment Internet than in treatment NoInternet. That is, for low-reciprocity workers gift exchange seems to be short-lived and they quickly succumb to the temptation of the Web, driving the crowding-out effects discussed above. Comparing conditions ChoiceInternet vs. Choice-NoInternet, time trends are less pronounced, and the overall impact of the manager's internet policy is relatively constant over time (see figure 8 in the appendix). 
Figure 3: Time variation in the effect of a wage gift on worker effort

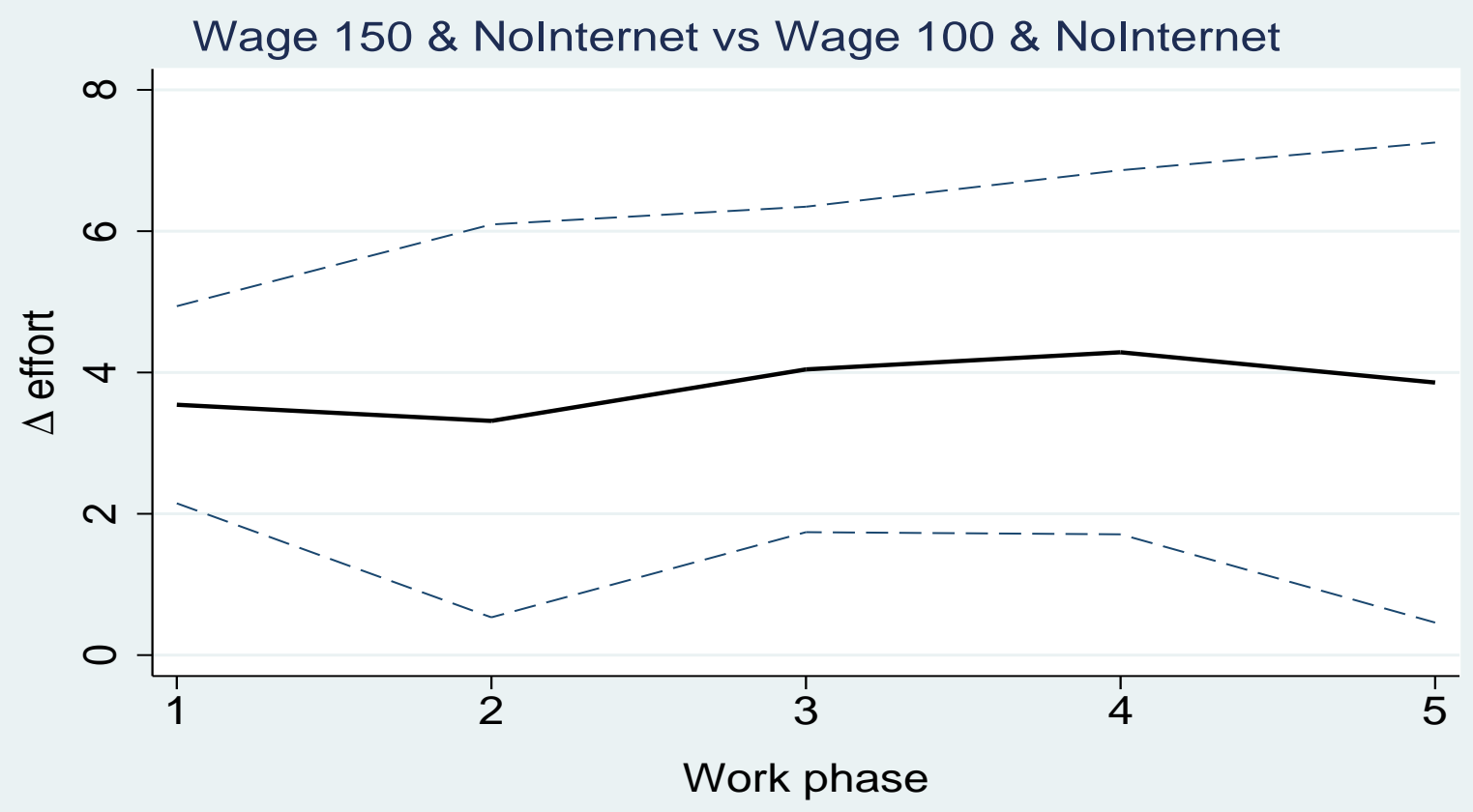

Notes: Predicted difference in effort (marginal effect at sample means of productivity and beliefs about the manager's effort) with 90-percent confidence interval derived from a random effects panel regression.

Figure 4: Crowding out of reciprocal motives over time

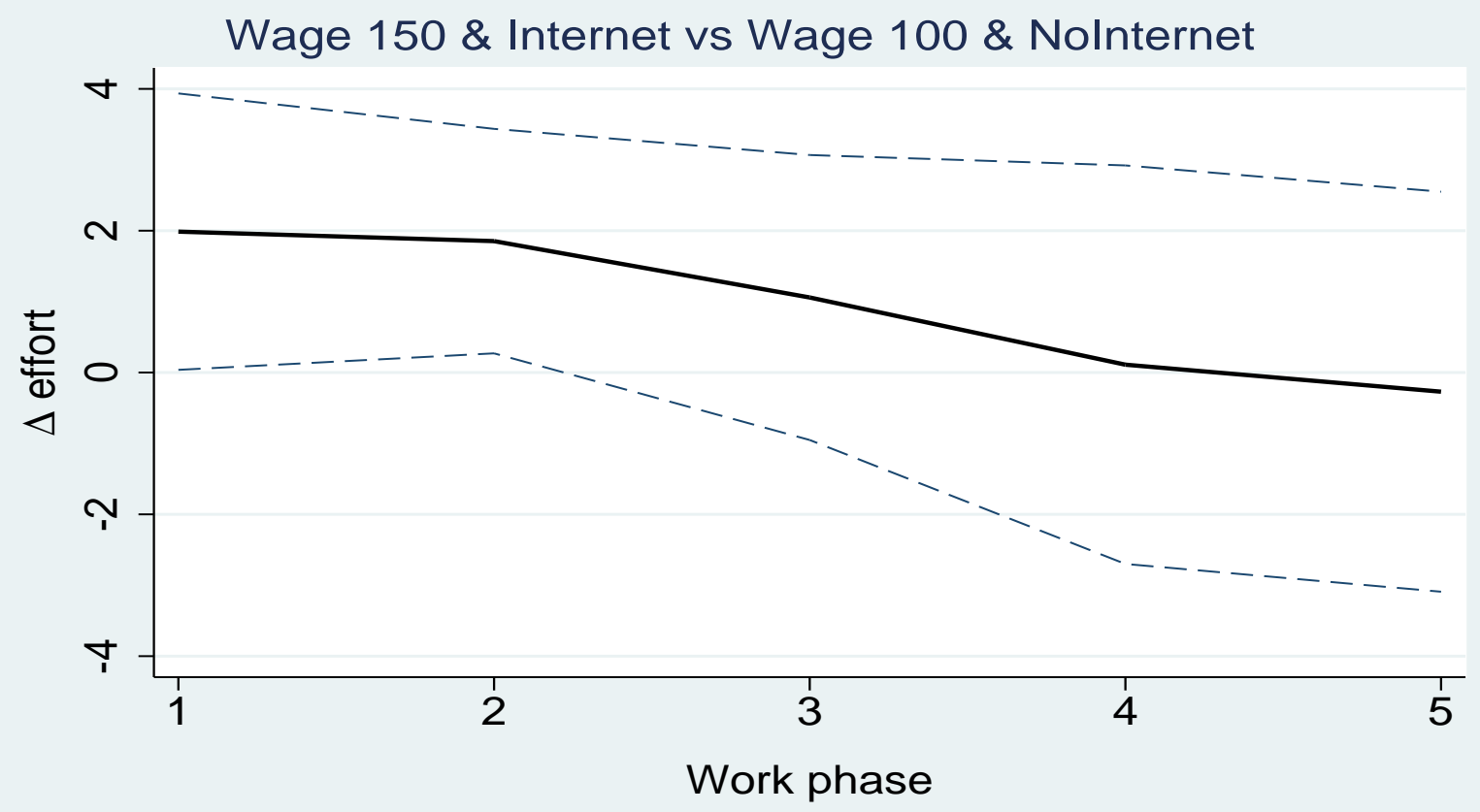

Notes: Predicted difference in effort (marginal effect at sample means of productivity and beliefs about the manager's effort) with 90-percent confidence interval derived from a random effects panel regression. 
Figure 5: Time variation in the effect of exogenous internet access at wage 150 on worker effort (treatments Internet vs. NoInternet)

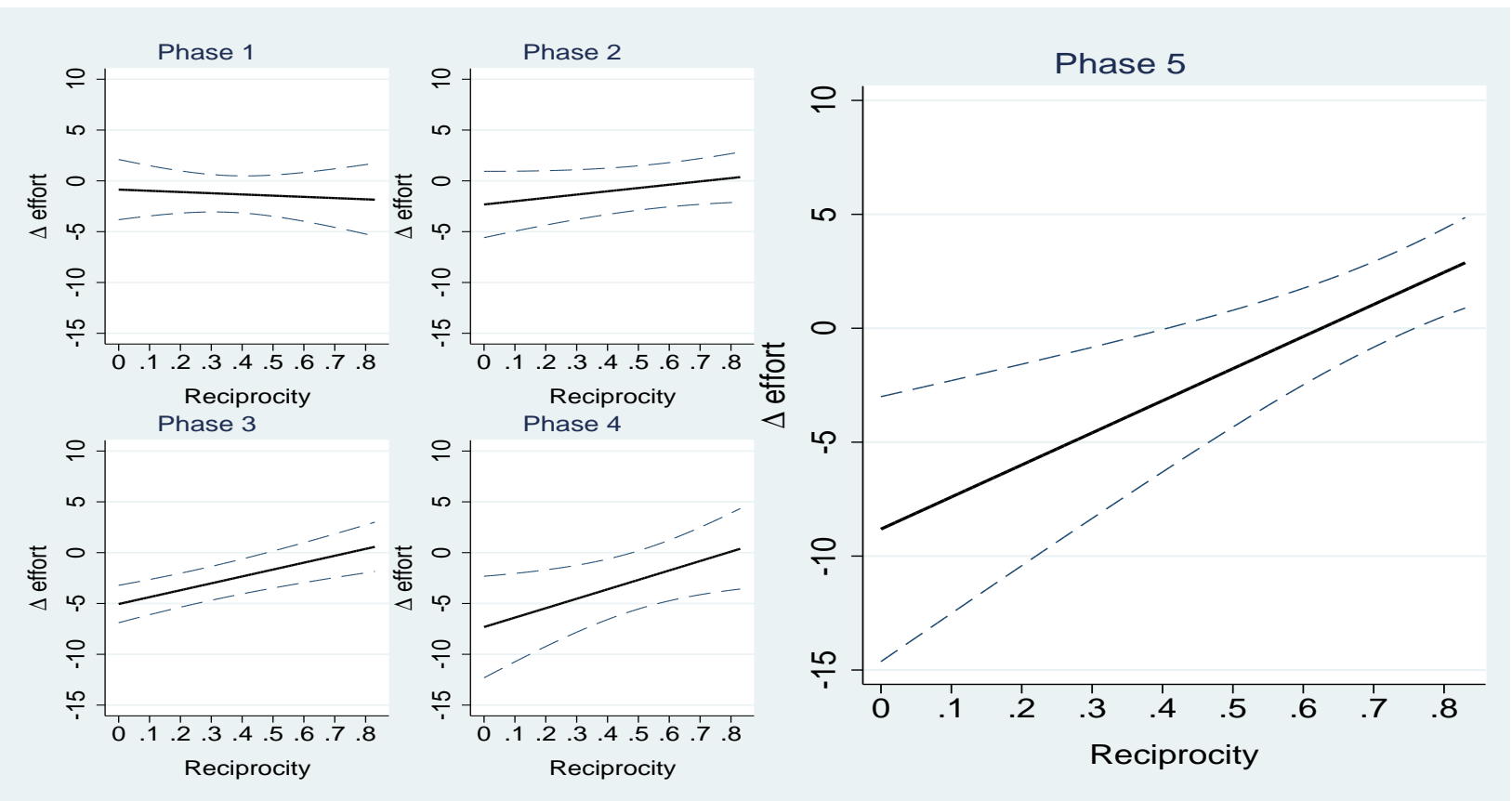

Notes: Predicted difference in effort (marginal effect at sample means of productivity and beliefs about the manager's effort) with 90-percent confidence interval. Reciprocity: average return rate in the trust game.

\subsection{Manager's choices: wages and internet access}

Table 6 shows regression estimates for manager's choices. The wage offered is positively related to how trusting a manager is (measured in the trust game). If workers are believed to be more productive, they are offered lower wages and a higher belief about worker effort provided also correlates with a higher wage offer. With these controls for beliefs, none of the treatment dummies Internet and Choice have a significant effect compared to the omitted category NoInternet. When looking at the decision whether to turn the internet on or off in treatment Choice, only beliefs about productivity and worker effort matter (see the last two columns in table 6). These results mostly stand in contrast to our hypotheses (prediction 5). In particular, they indicate that the access to the internet does not determine the wage policy. 
Table 6: Wage offers by managers

\begin{tabular}{|c|c|c|c|c|c|c|}
\hline \multirow[t]{2}{*}{ Variable } & \multicolumn{2}{|c|}{ OLS } & \multicolumn{4}{|c|}{ Logit (marginal effects) } \\
\hline & Wage $^{a}$ & Wage & High wage $^{b}$ & High wage & Turned-off $^{c}$ & Turned-off \\
\hline \multirow[t]{2}{*}{ Productivity } & 0.84 & 0.86 & 0.02 & 0.02 & -0.01 & -0.02 \\
\hline & $(0.57)$ & $(0.59)$ & $(0.01)$ & $(0.01)$ & $(0.02)$ & $(0.01)$ \\
\hline \multirow[t]{2}{*}{ Trust } & $8.05^{* * *}$ & $7.65^{* * *}$ & $0.10^{* *}$ & $0.10^{* *}$ & 0.07 & 0.05 \\
\hline & $(2.73)$ & $(2.74)$ & $(0.05)$ & $(0.05)$ & $(0.04)$ & $(0.05)$ \\
\hline \multirow[t]{2}{*}{ Belief about worker's productivity } & & $-0.71^{* *}$ & & $-0.02^{* *}$ & & $-0.02^{* *}$ \\
\hline & & $(0.27)$ & & $(0.01)$ & & $(0.01)$ \\
\hline \multirow[t]{2}{*}{ Belief about worker's effort } & & 0.15 & & $0.003^{*}$ & & $0.004^{*}$ \\
\hline & & $(0.10)$ & & $(0.002)$ & & $(0.002)$ \\
\hline NoInternet & \multicolumn{6}{|c|}{ Omitted category } \\
\hline \multirow[t]{2}{*}{ Internet } & $15.11^{*}$ & 14.54 & 0.20 & 0.20 & & \\
\hline & $(8.82)$ & $(9.19)$ & $(0.16)$ & $(0.17)$ & & \\
\hline \multirow[t]{2}{*}{ Choice } & 8.80 & 8.60 & 0.13 & 0.13 & & \\
\hline & $(7.90)$ & $(8.08)$ & $(0.15)$ & $(0.16)$ & & \\
\hline \multirow[t]{2}{*}{ Constant } & $97.58^{* * *}$ & $99.86^{* * *}$ & & & & \\
\hline & (10.18) & $(11.43)$ & & & & \\
\hline $\mathrm{R}^{2}$ & 0.10 & 0.12 & & & & \\
\hline $\mathrm{N}$ & 144 & 144 & 144 & 144 & 82 & 82 \\
\hline
\end{tabular}

Notes: Dependent variable: ${ }^{a}$ Wage $\in\{100,150,200\},{ }^{b} \mathrm{~A}$ dichotomous variable $=1$ if the wage offer $\geq 150$ and 0 otherwise. ${ }^{c} \mathrm{~A}$ dichotomous variable $=1$ if the internet is turned-on in the Choice treatment and 0 otherwise. Standard errors clustered at session level are in parentheses. ${ }^{*} p<0.10,{ }^{* *} p<0.05,{ }^{* * *} p<0.01$.

\subsection{Profits of the manager}

Higher wages lead to higher effort by the workers. But does it pay off in our setting to pay a generous wage? When pooling all treatments, the profit that the manager makes out of the worker $^{24}$ is significantly higher if the manager pays a wage of 100 than with a wage of 150 (t-test, one-sided, $p<0.01$ : -50.4 (39.5) vs. -74.5 (31.6) on average (std.dev.)). The same holds true for each individual treatment considered on its own. This shows that in our setting the workers' effort response is not large enough to offset the costs from a higher wage. This finding is consistent with the evidence from most field experiments, but in contrast to many of the results in lab experiments that typically are calibrated to provide scope for profitable wage increases. Further, the profits a manager makes out of a worker are significantly higher

\footnotetext{
${ }^{24}$ Defined by $1.5 \times$ effort of the worker minus the wage.
} 
in treatment NoInternet vs. Internet (t-test, one-sided, $p=0.02:-42.3$ (34.2) vs. -67.1 (45.3) on average (std.dev.)). However, in treatment Choice profits do not differ significantly across the decisions to turn the internet off or on (t-test, two-sided, $p=0.72$ : -71.1 (37.4) vs. -68.2 (32.6) on average (std.dev.)). Overall, the profits a manager makes out of the worker are highest if he pays a wage of 100 and the internet is off by default. In the Choice treatment the profit maximizing wage-internet policy is a wage of 100 and internet access denied.

\section{Conclusion}

We conduct a real-effort experiment to test whether workers reciprocate generous wages when they are tempted by the internet. Workers provide low effort when they receive an 'unfair' wage - no matter whether they have internet access or not. Yet, when receiving a 'fair' wage, workers provide more effort when the internet is off than when it is on, and we observe that temptations may even completely crowd out reciprocal motives. Further, we investigate how an active policy of restricting the usage of the internet affects workers' motivation. While such a policy provides a commitment device to workers not to get distracted from their job, it may be perceived as excessive control. We observe that for highly reciprocal workers the control aspect dominates. Further, for these workers "freedom from control" is at least as important as a generous wage. For non-reciprocal workers the commitment aspect dominates.

In our experiment, internet access is not required to perform the real effort task and

managers face the "extreme", 0-1, choice whether to fully deny access to the internet or to fully allow it. In real firms, the internet is needed for many office jobs and hence access to the internet is not technically restricted, or if there are restrictions, then these refer to the usage of certain internet contents like social media. Yet, while the choices in our experiment are more extreme, we believe that they still mirror the effects of restricting the use of social media in real firms: For most jobs accessing social media during work has no benefit for the job itself - akin to the internet having no benefit for our real effort task.

We studied one particular temptation that is present in real world firms: the internet. But of course, in reality, other temptations exist, such as visiting the coffee machine, having extended chats with colleagues, smoking breaks or making private phone calls. We have 
chosen the internet because we believe that most people value access to the internet and thereby the internet is, at least to some extent, a representative source of temptation. While we of course cannot conclude from our experiment whether the same results carry over to other sources of temptation, and we do not know whether and how different temptations interact, our finding that reciprocal workers respond positively to "freedom of control" does reveal that there can be hidden costs of control when firms remove a temptation. This is important in view of the variety of control mechanisms at the disposal of firms, including not just policies about internet usage but also regulations regarding when and how often employees may take breaks, usage of private mobile phones at work, whether employees may work from home or whether and how working hours are monitored.

\section{References}

Abeler, Johannes, Armin Falk, Lorenz Götte, and David Huffman, "Reference Points and Effort Provision," American Economic Review, 2011, 101 (2), 470-492.

Akerlof, George A, "Labor Contracts as Partial Gift Exchange," Quarterly Journal of Economics, 1982, pp. 543-569.

and Janet L Yellen, "The Fair Wage-Effort Hypothesis and Unemployment," Quarterly Journal of Economics, 1990, pp. 255-283.

Angrist, Joshua D and Jörn-Steffen Pischke, Mostly Harmless Econometrics: An Empiricist's Companion, Princeton, NJ: Princeton University Press, 2008.

Bellemare, Charles and Bruce Shearer, "Gift Giving and Worker Productivity: Evidence From a Firm-level Experiment," Games and Economic Behavior, 2009, 67 (1), 233-244.

Brandts, Jordi and Gary Charness, "Do Labour Market Conditions Affect Gift Exchange? Some Experimental Evidence," Economic Journal, 2004, 114 (497), 684-708.

Brüggen, Alexander and Martin Strobel, "Real Effort Versus Chosen Effort in Experiments," Economics Letters, 2007, 96, 232-236. 
Charness, Gary, "Responsibility and Effort in an Experimental Labor Market," Journal of Economic Behavior 65 Organization, 2000, 42 (3), 375-384.

Cohn, Alain, Ernst Fehr, and Lorenz Goette, "Fair Wages and Effort Provision: Combining Evidence from a Choice Experiment and a Field Experiment," mimeo 2013.

Corgnet, Brice, Roberto Hernán-González, and Stephen Rassenti, "Real Effort, Real Leisure and Real-time Supervision: Incentives and Peer Pressure in Virtual Organizations," Technical Report, Chapman University, Economic Science Institute 2011.

Cox, James C, Daniel Friedman, and Steven Gjerstad, "A Tractable Model of Reciprocity and Fairness," Games and Economic Behavior, 2007, 59 (1), 17-45.

, and Vjollca Sadiraj, "Revealed Altruism," Econometrica, 2008, 76 (1), 31-69.

Davenport, Thomas H., "Rethinking Knowledge Work: A Strategic Approach," McKinsey Quarterly, February 2011. http://www.mckinsey.com/insights/organization/ rethinking_knowledge_work_a_strategic_approach (last accessed November 2014).

Dufwenberg, Martin and Georg Kirchsteiger, "A Theory of Sequential Reciprocity," Games and Economic Behavior, 2004, 47 (2), 268-298.

Dux, Paul E, Jason Ivanoff, Christopher L Asplund, and René Marois, "Isolation of a Central Bottleneck of Information Processing with Time-resolved fMRI," Neuron, 2006, 52 (6), 1109-1120.

Englmaier, Florian and Stephen Leider, "Gift Exchange in the Lab-It is not (only) how much you give...," mimeo 2010.

Falk, Armin and Michael Kosfeld, "The Hidden Costs of Control," American Economic Review, 2006, pp. 1611-1630.

Fehr, Ernst and Klaus M Schmidt, "A Theory of Fairness, Competition, and Cooperation," Quarterly Journal of Economics, 1999, pp. 817-868.

, Georg Kirchsteiger, and Arno Riedl, "Does Fairness Prevent Market Clearing? An Experimental Investigation," Quarterly Journal of Economics, 1993, pp. 437-459. 
__ _ _ and _ _ , "Gift Exchange and Reciprocity in Competitive Experimental Markets," European Economic Review, 1998, 42 (1), 1-34.

Fischbacher, Urs, "z-Tree: Zurich Toolbox for Ready-made Economic Experiments," Experimental Economics, 2007, 10 (2), 171-178.

Gneezy, Uri and John A List, "Putting Behavioral Economics to Work: Testing for Gift Exchange in Labor Markets Using Field Experiments," Econometrica, 2006, 74 (5), $1365-1384$.

Hagemann, Petra, "On the Benefits of Control in Teams," mimeo, University of Cologne 2007.

Halliday, Josh, "Eleven Work and Pensions Civil Servants Sacked for Using Twitter or Facebook," The Guardian, 9 January 2013. http://www.theguardian.com/ technology/2013/jan/09/eleven-civil-servants-sacked-twitter (last accessed November 2014).

Hennig-Schmidt, Heike, Abdolkarim Sadrieh, and Bettina Rockenbach, "In Search of Workers' Real Effort ReciprocityA Field and a Laboratory Experiment," Journal of the European Economic Association, 2010, 8 (4), 817-837.

Houser, Daniel, Daniel Schunk, Joachim K Winter, and Erte Xiao, "Temptation and Commitment in the Laboratory," Technical Report 4882010.

Kube, Sebastian, Michel André Maréchal, and Clemens Puppe, "The Currency of Reciprocity: Gift Exchange in the Workplace," American Economic Review, 2012, 102 (4), 1644-1662.

__ _ _ and _ _ , "Do Wage Cuts Damage Work Morale? Evidence From a Natural Field Experiment," Journal of the European Economic Association, 2013, 11 (4), 853870.

Maximiano, Sandra, Randolph Sloof, and Joep Sonnemans, "Gift Exchange in a Multi-Worker Firm," Economic Journal, 2007, 117 (522), 1025-1050. 
Schnedler, Wendelin and Radovan Vadovic, "Legitimacy of Control," Journal of Economics 8 Management Strategy, 2011, 20 (4), 985-1009.

Simonson, Itamar, "Choice Based on Reasons: The Case of Attraction and Compromise Effects," Journal of Consumer Research, 1989, pp. 158-174.

SüddeutscheZeitung, "Britische Beamte wegen Facebook und Twitter gefeuert," 1 January 2013. http://www.sueddeutsche.de/politik/ soziale-netzwerke-britische-beamte-wegen-facebook-und-twitter-gefeuert-1. 1569654 (last accessed November 2014).

Trougakos, John P and Ivona Hideg, "Momentary Work Recovery: The Role of Withinday Work Breaks," Current Perspectives on Job-stress Recovery: Research in Occupational Stress and Well Being, 2009, 7, 37-84.

Ziegelmeyer, Anthony, Katrin Schmelz, and Matteo Ploner, "Hidden Costs of Control: Four Repetitions and an Extension," Experimental Economics, 2012, 15 (2), 323340. 


\section{Appendix}

\section{Theoretical model}

Similar to Kube et al. (2013), we adopt a simplified version of the model by Cox et al. (2007). The utility function of the worker is given by:

$$
u_{w}=x_{w}+\theta x_{m},
$$

where $x_{w}=w-\alpha c\left(e_{m}\right)+I$ is the direct payoff of the worker (the wage minus his effort costs), $x_{m}=v\left(e_{m}\right)-\alpha c\left(e_{m}\right)+v\left(e_{w}\right)-w+150+I, v(e)=1.5 e$, is the payoff of the manager, and $\theta \in \mathbb{R}$ is the "emotional state" of the worker. It is larger when the worker feels treated kindly by the manager than when he feels treated unkindly. In the latter case, $\theta$ is negative for most individuals (Cox, Friedman and Gjerstad 2007). I is a positive constant capturing the joy of surfing the internet if it is on.

The parameter $\theta$ depends on the wage and the treatment, i.e., $\theta(w, \tau)$, where $\tau \in$ $\{C I, C N I, I, N I\}$ refers either to treatment Choice, where the manager decides between turning the internet on $(C I)$ or off $(C N I)$, or to the exogenous internet-on policy in treatment Internet $(I)$, or to the exogenous internet-off policy in treatment NoInternet $(N I)$. As argued in the main text, the wage of 150 should be perceived as kind, while the wage of 100 as unkind. Further, turning the internet on should be perceived as kind, while turning it off as unkind. Thus, $\theta(100, \tau)<\theta(150, \tau)$, with $\theta(100, \tau)<0$ for most individuals and $\theta(w, C N I)<\theta(w, C I)$. In contrast, whether the internet is on or off by default should not influence the kindness of a wage, i.e., $\theta(w, I)=\theta(w, N I)$ (see also the arguments given below for the case where $\theta$ is endogenous).

The parameter $\alpha \in\{\underline{\alpha}, \bar{\alpha}\}, \bar{\alpha}>\underline{\alpha}$, captures the impact of internet access on opportunity

costs. Specifically, $\alpha=\underline{\alpha}>0$ if there is access to the internet and $\alpha=\bar{\alpha}>\underline{\alpha}$ without access. Plugging in $x_{w}$ and $x_{m}$ into the utility function, we see that the worker solves

$$
\max _{\bar{e} \geq e \underline{e}} w-\alpha c\left(e_{w}\right)+\theta v\left(e_{w}\right)+\kappa,
$$

where $\kappa$ captures all constant terms. Thus, the optimal effort is characterized by:

$$
\theta v^{\prime}\left(e_{w}\right) \leq \alpha c^{\prime}\left(e_{w}\right) \quad \text { with equality for } \bar{e}>e_{w}>\underline{e} .
$$


Workers with $\theta=0$ (non-reciprocal workers) provide the minimum effort. Similar, if $\theta(100, \tau)<0$ the worker provides the minimum effort when offered the low wage - irrespective of whether the internet is on or off (by choice or default). If $\theta(100, \tau)>0$ workers provide more than the minimum effort. From $\theta(150, \tau)>\theta(100, \tau)$ it follows that those workers still provide less effort with a wage of 100 than with a wage of 150 (unless they are already at their productivity limit at a wage of 100). Those workers who provide more than the minimum effort $\underline{e}$ (and less than $\bar{e}$ ) work more when the internet is off than when it is on by default, because $\bar{\alpha}>\underline{\alpha}$.

If turning on the internet is perceived as kind, then $\theta(w, C I)>\theta(w, I)$ and those workers who are working more than the minimum effort should work more when the internet is turned on by choice rather than by default. Whether turning the internet on or off has a positive or negative impact on effort depends on whether $\underline{\alpha} / \theta(w, C N I)$ is smaller or larger than $\bar{\alpha} / \theta(w, C I)$. The larger $\theta(w, C I)$ is in relation to $\theta(w, C N I)$, i.e., the more positive the worker perceives kind actions, the more likely it is that turning the internet on has a positive effect on effort.

Finally, considering the subgames after the policy choice, the effort of the manager solves $\max _{\bar{e} \geq e \geq \underline{e}} v\left(e_{m}\right)-\alpha c\left(e_{m}\right)$. Thus, as $\bar{\alpha}>\underline{\alpha}$, managers provide more effort when the internet is off than when it is on. Further, for $\theta<1$ it follows that managers provide more effort than workers.

\section{Predictions of social preference models: could workers perceive the same wage differently in treatments Internet and NoInternet?}

\section{Dufwenberg and Kirchsteiger (2004)}

According to Dufwenberg and Kirchsteiger (2004) the kindness of the manager to the worker is given by:25

$$
\begin{gathered}
k_{m w}\left(w, \hat{e}_{w}\right)=u_{w}\left(w, \hat{e}_{w}\right)-u_{w}^{e}\left(\hat{e}_{w}\right), \text { where } \\
u_{w}^{e}\left(\hat{e}_{w}\right)=\sigma\left[\max _{w} u_{w}\left(w, \hat{e}_{w}\right)\right]+(1-\sigma)\left[\min _{w} u_{w}\left(w, \hat{e}_{w}\right)\right],
\end{gathered}
$$

\footnotetext{
${ }^{25}$ The manager's income from his own effort choice cancels out from $k_{m w}$. So we suppress the arguments relating to the manager's effort.
} 
and $\hat{e}_{w}$ denotes the belief of the manager about the worker's effort. It is immediate that $\alpha c\left(\hat{e}_{w}\right)$ cancels out from the kindness function, i.e., the internet does not directly affect the kindness of a certain wage offer.

Similarly, the belief of the manager about how kind the worker is to him is given by ${ }^{26}$

$$
\begin{gathered}
\lambda_{m w m}\left(\tilde{w}, \hat{e}_{w}\right)=u_{m}\left(\tilde{w}, \hat{e}_{w}\right)-u_{m}^{e}(\tilde{w}), \text { where } \\
u_{m}^{e}(\tilde{w})=\sigma\left[\max _{\underline{\underline{e}} \leq \hat{e}_{w} \leq \bar{e}} u_{m}\left(\tilde{w}, \hat{e}_{w}\right)\right]+(1-\sigma)\left[\min _{\underline{\underline{e}} \leq \hat{e}_{w} \leq \bar{e}} u_{m}\left(\tilde{w}, \hat{e}_{w}\right)\right],
\end{gathered}
$$

and $\tilde{w}$ denotes the belief of the manager about the worker's belief about the manager's wage policy. Plugging in, we get that $\lambda_{\operatorname{mwm}}\left(\tilde{w}, \hat{e}_{w}\right)=1.5\left(\hat{e}_{w}-e_{\max }\right)$, where $e_{\max }=$ $\max _{\hat{e}_{w} \leq \bar{e}} u_{m}\left(\tilde{w}, \hat{e}_{w}\right)$. Note that $e_{\max }$ maximizes the manager's utility and thus is is independent of the worker's effort costs and thus independent of $\alpha$ (the internet parameter). Further note that $\tilde{w}$ cancels out from $\lambda_{m w m}\left(\tilde{w}, \hat{e}_{w}\right)$.

The utility of the manager is then (suppressing his own effort decision):

$$
\begin{aligned}
& u_{m}(w, \hat{e})+k_{m w}\left(w, \hat{e}_{w}\right) \times \lambda_{m w m}\left(\tilde{w}, \hat{e}_{w}\right) \\
& =1.5 \hat{e}_{w}-w+\left(w-\left(\sigma w_{\min }+(1-\sigma) w_{\max }\right)\right) \times 1.5\left(\hat{e}_{w}-\sigma e_{\max }\right) .
\end{aligned}
$$

The utility of the worker is:

$$
\begin{aligned}
& u_{w}\left(\hat{w}, e_{w}\right)+k_{w m}\left(\hat{w}, e_{w}\right) \times \lambda_{w \operatorname{mw}}\left(\hat{w}, \tilde{e}_{w}\right) \\
& =w-\alpha c(e)+\left(\hat{w}-\left(\sigma w_{\min }+(1-\sigma) w_{\max }\right)\right) \times 1.5\left(e_{w}-e_{\max }\right),
\end{aligned}
$$

where $\tilde{e}_{w}$ is the belief of the worker about the manager's belief about the worker's effort. It however cancels out.

When making his effort choice, the worker must hold the belief that with probability 1 one the wage is the actual wage that the manager offers. If $w>\sigma \hat{w}_{\text {min }}+(1-\sigma) \hat{w}_{\text {max }}$, then his effort is characterized by $\alpha c^{\prime}\left(e^{*}\left(\alpha, \lambda_{w m w}\right)\right)=1.5 \lambda_{w m w}$. Else he chooses the minimum effort, i.e., $e^{*}\left(\alpha, \lambda_{w m w}\right)=\underline{e}$. If the manager believes that the worker provides $\hat{e}>\sigma \hat{e}_{\max }$, then he might choose a wage above the minimum wage. Else he chooses the minimum wage. In equilibrium $\hat{e}=e^{*}\left(\alpha, \lambda_{w m w}\right)$.

\footnotetext{
${ }^{26}$ Again, the manager's income from his own effort choice cancels out from $\lambda_{m w m}$. So we suppress the arguments relating to the manager's effort.
} 
The worker's optimal effort is a function of $\alpha$ and $\lambda_{w m w}$. Note that $\lambda_{w m w}$ is independent of $\alpha$ (the exogenous availability of the internet) and the worker's effort. The parameter $\alpha$ influences the worker's effort directly (via the costs function). And, it influences (via the manager's belief) the probability that the manager pays a higher wage. Thus, if a manager pays the same wage in treatment Internet and NoInternet, $\lambda_{w m w}$ is the same in both treatments and $\alpha$ only has a direct impact on effort. This result would also hold if one assumed that the worker (and manager) derives a costant utility from surfing the internet, i.e., receives an extra, additive intrinsic utility component $I$ if the internet is on (see the previous section for the addition of such a component in the utility function).

\section{Cox, Friedman and Sadiraj (2008)}

Cox, Friedman and Sadiraj (2008) use opportunity sets to define reciprocity. Let $u_{w}=$ $w-\alpha c\left(e_{w}\right)$ be the worker's payoff and $u_{m}=1.5 e_{w}-w+1.5 e_{m}-\alpha c\left(e_{w}\right)+100$ be the manager's payoff. Opportunity set $G$ for a worker is more generous than opportunity set $F$ if for maximum achievable own payoff $\left(u_{w}^{*}\right)$ and other's payoff $\left(u_{m}^{*}\right)$, we have $u_{w}^{*}(G) \geq u_{w}^{*}(F)$ and $u_{w}^{*}(G)-u_{w}^{*}(F) \geq u_{m}^{*}(G)-u_{m}^{*}(F)$. The reciprocity axiom says that if a manager chooses a more generous opportunity set, then the worker's preferences become more altruistic 27

Note that $\alpha$ is not in the opportunity set of the manager in Internet and NoInternet. Yet, we can apply the model of Cox et al. (2008) to examine whether a wage of 150 compared to a wage of 100 could be perceived as non-generous in treatment Internet but as generous in treatment NoInternet (this is the problematic case for identification). In both treatments, the worker can choose an effort of zero and thereby achieve a payoff that equals the wage. Thus, $u_{w}^{*}(150, \alpha)-u_{w}^{*}(100, \alpha)=50$ irrespective of the treatment. The maximal achievable payoff for the manager is $u_{m}(\alpha, 150)=1.5 \bar{e}_{w}(\alpha)-150$ and $u_{m}(\alpha)=1.5 \bar{e}_{w}(\alpha)-100$, where $\bar{e}(\alpha)$ is the maximum effort of the worker in the respective treatment. Thus, $u_{w}^{*}(150, \alpha)-u_{w}^{*}(100, \alpha)=$ $50>0$ and $u_{w}^{*}(150, \alpha)-u_{w}^{*}(100, \alpha)=50 \geq u_{m}^{*}(150, \alpha)-u_{m}^{*}(100, \alpha)=-50$. This holds irrespective of $\alpha$, i.e., irrespective whether the internet is on or off by default. Thus, a wage of 150 relative to a wage of 100 is perceived as equally generous in both treatments.

\footnotetext{
${ }^{27} \mathrm{~A}$ preference ordering $\mathcal{A}$ over "my" and "your" payoff is considered more altruistic than another preference ordering $\mathcal{B}$ if we the willingness to pay to increase the other's payoff in terms of own payoff is larger under $\mathcal{A}$ than under $\mathcal{B}$.
} 
One could extent the definition of Cox et al. (2008) to compare the generosity of different exogenous environments. Conditioning on the wage, the maximal achievable payoff for the worker in Internet and NoInternet is 150. He can achieve this wage by choosing $e=0$. The maximal achievable payoff for the manager is $u_{m}(\bar{\alpha})=1.5 e_{w}(\bar{\alpha})-w$ and $u_{m}(\underline{\alpha})=$ $1.5 e_{w}(\underline{\alpha})-w$. As argued before, $e(\bar{\alpha}) \leq e(\underline{\alpha})$ because of the higher costs of the worker when having internet access. Thus, conditioning on the wage, we have $u_{w}^{*}(\bar{\alpha})-u_{w}^{*}(\underline{\alpha})=0$ and $0=u_{w}^{*}(\bar{\alpha})-u_{w}^{*}(\underline{\alpha}) \geq u_{m}^{*}(\bar{\alpha})-u_{m}^{*}(\underline{\alpha})=e(\bar{\alpha})-e(\underline{\alpha}) \leq 0$. In other words, if at all, a wage of 150 in treatment Internet should be perceived as more generous than a wage of 150 in treatment NoInternet. This result would be strengthened if one assumed that the worker (and manager) derives utility from surfing the internet, i.e., receives an extra, additive intrinsic utility component $I$ if the internet is on (see the previous section for the addition of such a component in the utility function).

\section{Fehr and Schmidt (1999)}

The Fehr and Schmidt (1999) utility function of player $i$ in a two-player game is given by: $u\left(x_{i}, x_{j}\right)=x_{i}-a_{i} \max \left\{x_{j}-x_{i}, 0\right\}-b_{i}\left\{x_{i}-x_{j}, 0\right\}$, where $x_{i}$ is a player's monetary payoff, $a_{i}$ is the weight attached to disadvantageous inequality and $b_{i}$ is the weight attached to advantageous inequality. Thus, the worker's utility can be written as $w-\alpha c\left(e_{w}\right)-$ $a_{i} \max \left\{1.5\left(e_{w}+e_{m}\right)+150-w-w, 0\right\}-b_{i}\left\{w-\left(1.5\left(e_{w}+e_{m}\right)+150-w\right), 0\right\}$. It is immediate that $\alpha$ does not influence the utility from advantageous or disadvantageous fairness, i.e., a given wage is not perceived more or less fair dependent on whether the internet is on or off. This result also holds if one assumed that the worker (and manager) derives (dis)utility from surfing the internet, i.e., receives an extra, additive intrinsic utility component $I$ if the internet is on (see the previous section for the addition of such a component in the utility function). 


\section{Additional figures and tables}

Figure 6: Interaction effects between wages and internet (attempted tables).

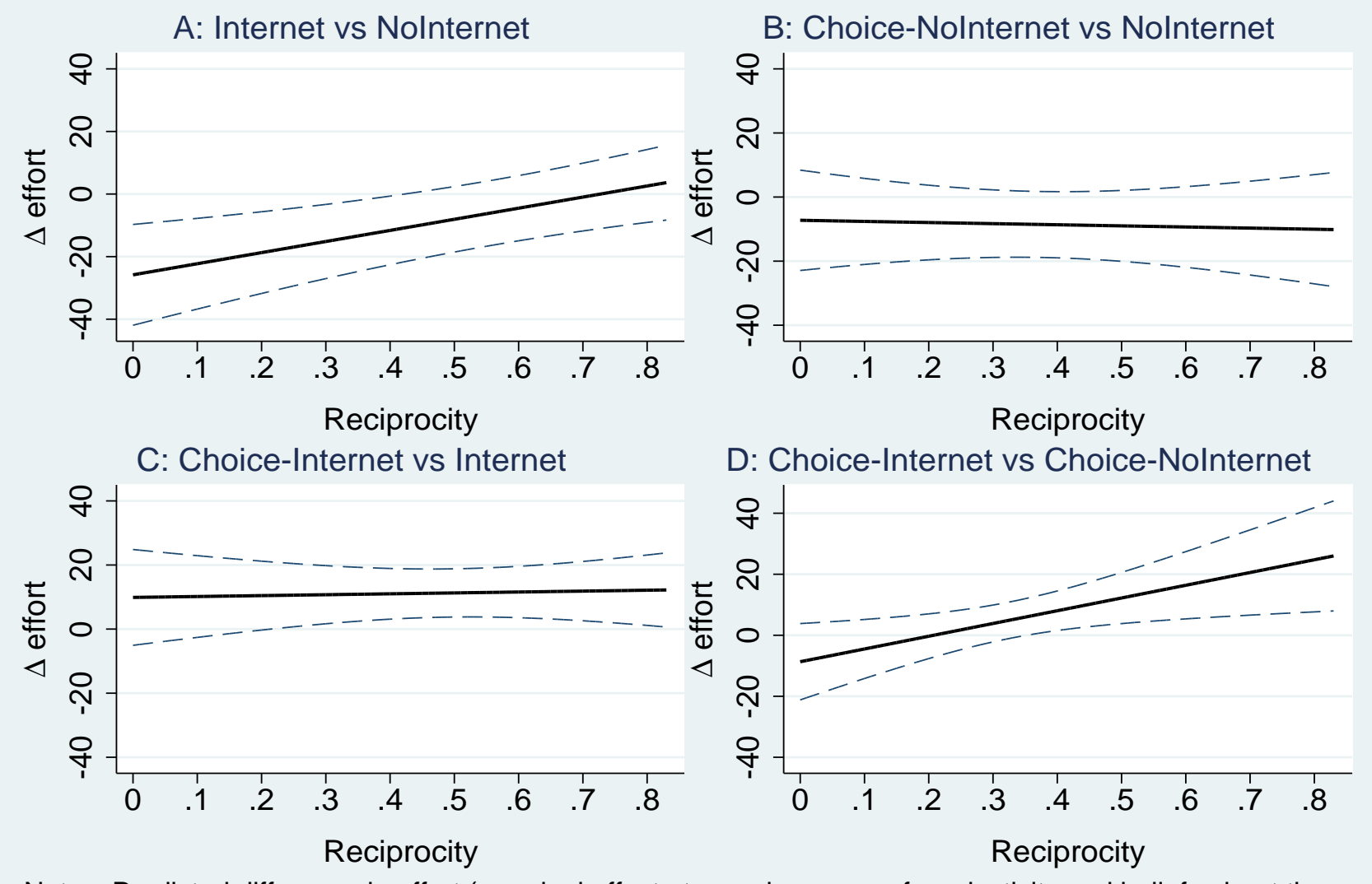

Notes: Predicted difference in effort (marginal effect at sample means of productivity and beliefs about the manager's effort) with 90-percent confidence interval. Reciprocity: average return rate in the trust game.

Attempted tables range from zero to 179 (except for one outlier with 687 attempted tables that is dropped for the analysis), compared to our effort measure of correct tables which ranges from zero to 124 . 
Figure 7: Probability of periods of inactivity at wage 150
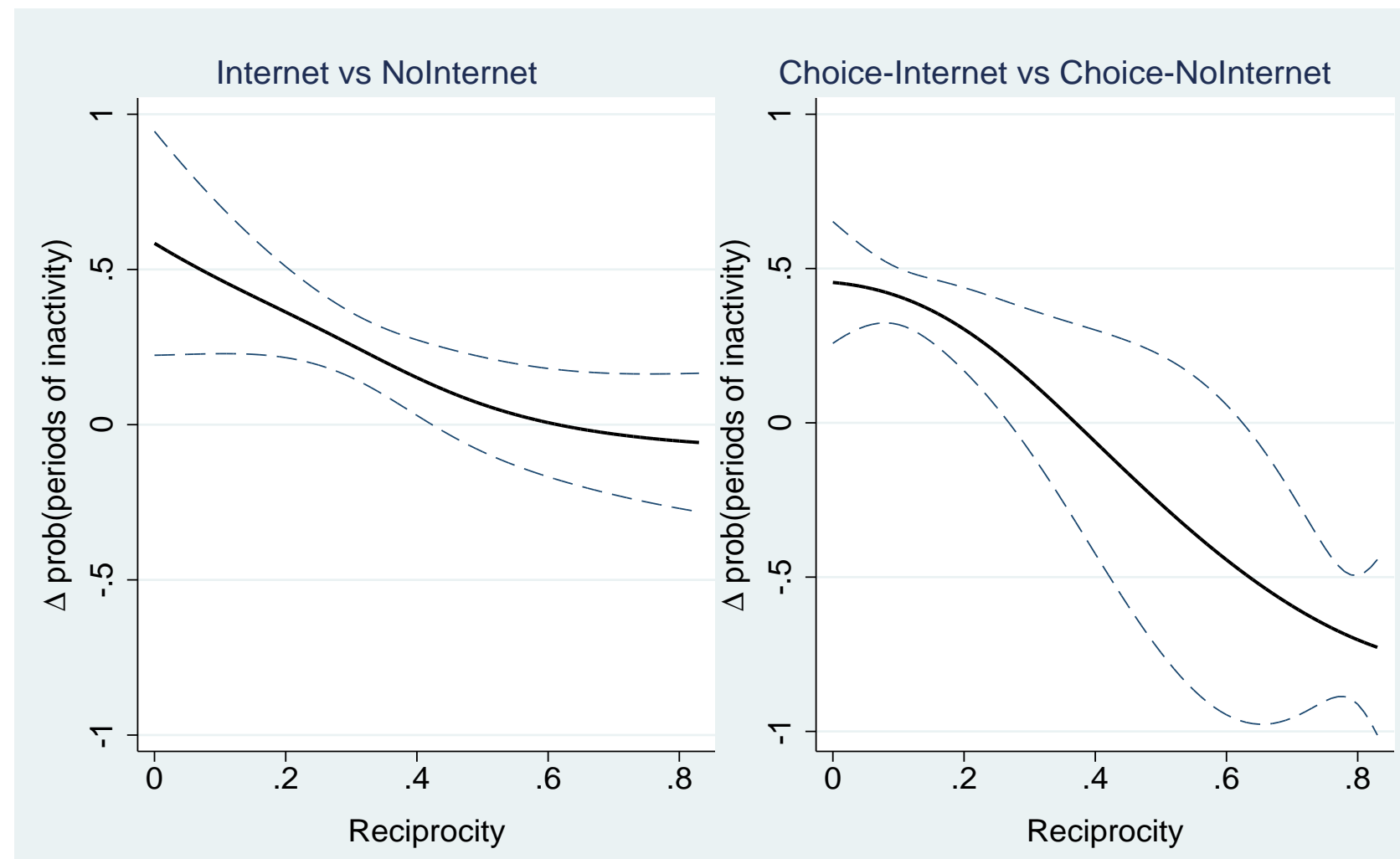

Notes: Outcome variable: Dichotomous variable $=1$ if participant had at least one period of inactivity of more tr 2 minutes and $=0$ otherwise. Plots: Marginal effect at sample mean of productivity and beliefs about the manager's effort with 90-percent confidence interval. Reciprocity: average return rate in the trust game.

About half of the workers have at least one period of inactivity greater than 2 minutes. For managers that figure is less than 18 percent in all treatments. This measure hence captures more extreme shirking than our effort measure of tables counted somehow adjusted for productivity does. 
Figure 8: Time variation in the effect of the manager's internet policy at wage 150 on worker effort (treatments Choice-Internet vs. Choice-NoInternet)

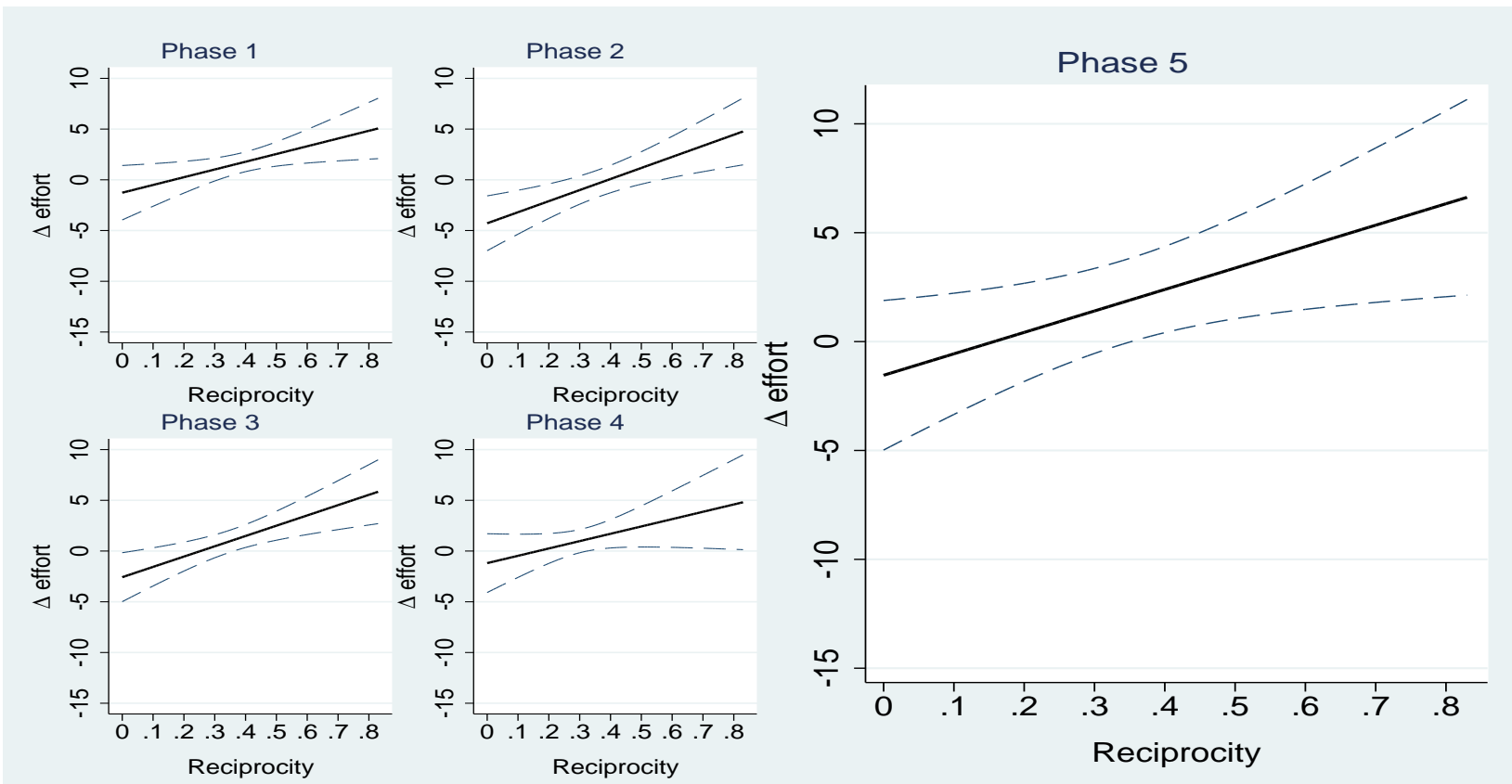

Notes: Predicted difference in effort (marginal effect at sample means of productivity and beliefs about the manager's effort) with 90-percent confidence interval. Reciprocity: average return rate in the trust game. 


\section{Instructions}

\section{Overview and Information}

Welcome You are now taking part in an economic experiment. If you read the following instructions carefully, you can, depending on your decisions and the decisions of other participants, earn a considerable amount of money. It is prohibited to communicate with the other participants during the experiment. Should you have any questions please raise your hand and we will come to you.

Overview The experiment consists of $\mathbf{5}$ parts. Please start by reading the instructions for the first part carefully. You will receive the instructions for the second part after the first part is finished. And so on.

Earnings Each part gives you an opportunity to earn money. In addition, you get a show-up fee of $\mathbf{3 0} \mathbf{~ k r}$. Your total pre-tax earnings are the sum of the earnings for each part and the show-up fee.

\section{Details for Part 1}

\section{Task}

In this part of the experiment, your task is to count zeros in a series of tables. The figure shows the work screen you will use later: [The screenshot was used for Treatments Internet and Choice. In Treatment NoInternet the sentence "The internet is off during part 1"was not displayed]

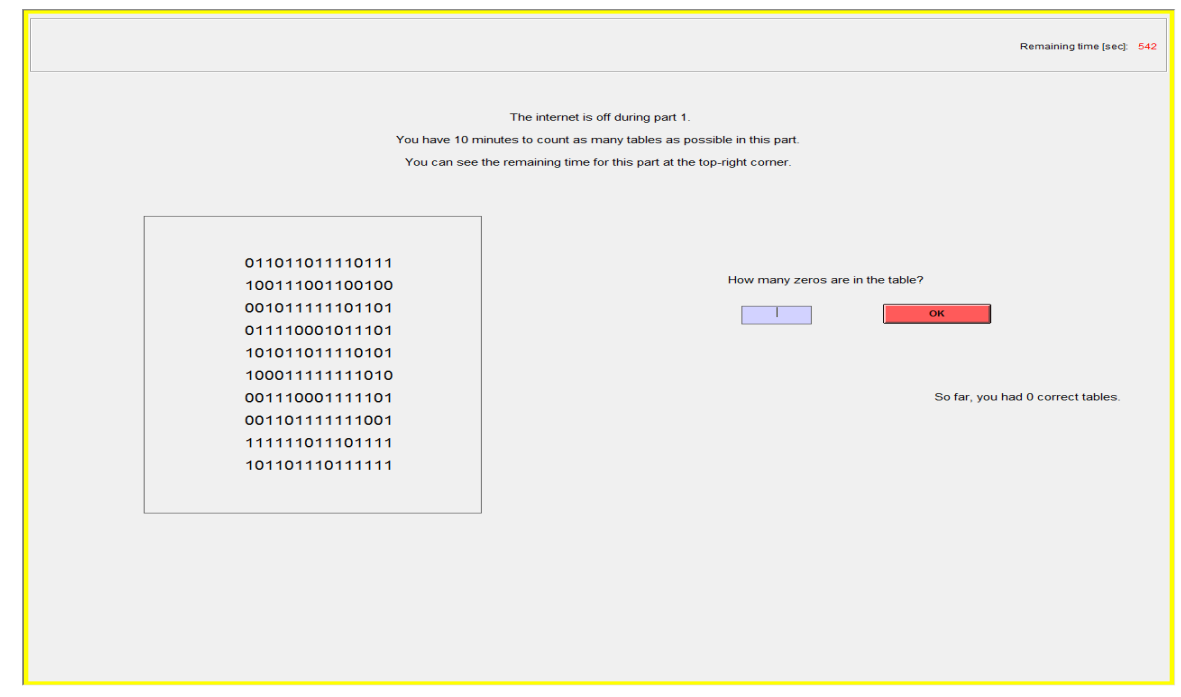


Enter the number of zeros that you count into the box next to the table and then press the OK-button. Thereafter, the next table appears.

After pressing the OK-button you are informed whether you counted the number of zeros correctly or not. Below the entry field, you can see how many tables you have counted correctly so far.

Part 1 lasts 10 minutes. The remaining time (in seconds) is displayed in the upper right hand corner of the screen.

Treatment Internet and Choice: There is no access to the internet during the first part of the experiment.

\section{Counting tips}

Of course you can count the zeros any way you want. Speaking from experience, however, it is helpful to always count two zeros at once and multiply the resulting number by two at the end. In addition you miscount less frequently if you track the number you are currently counting with the mouse cursor.

\section{Earnings in part 1}

You receive $1.5 \mathrm{kr}$. for each table where you count the number of zeros correctly. You earn nothing for tables where you miscount the number of zeros.

\section{Example}

You count the number of zeros correctly in $\mathbf{9}$ tables and you miscount 1 table.

- Your earnings in part 1 are therefore: $13.5 \mathrm{kr} .=9 \times 1.5 \mathrm{kr}$.

\section{Practice question}

Please answer the following question: Assume that you count the number of zeros correctly in 4 tables and you miscount 7 tables.

- What are your earnings in part 1 ?

After all participants have answered the practice question correctly, the experimenter will start the first part of the experiment. 


\section{Details for Part 2}

\section{Your role}

In the beginning of part 2, you are randomly chosen to be either a "Manager" or a "Worker". Each Worker is randomly matched with a Manager. You learn in the beginning of part 2 which role you have.

\section{Task}

Once again, no matter if you are a Manager or a Worker, you count zeros in a series of tables - just like the tables you counted before. Again enter the number of zeros that you count in the table into the box next to the table and then press the OK-button. Thereafter, the next table appears.

After pressing the OK-button you will be informed whether you counted the number of zeros in the table correctly or not. Below the entry field, you can see how many tables you have counted correctly so far.

The second part of the experiment lasts 62 minutes. Of these 62 minutes, 50 minutes are reserved to work on tables and 12 minutes are reserved for breaks. The 50 minutes reserved to work on tables are divided into 5 phases. Each phase lasts 10 minutes. After each phase, there will be a break for 3 minutes. During this break you cannot work on any tables. You are not allowed to leave your seat or to talk to other participants during a break. The remaining time of each phase, as well as the phase you are in, are displayed on the screen.

Treatment Internet: There will be internet access during the whole duration of part 2 and you can access the internet at any point you like. Note that you can also use the address line of the browser to search the internet. We will delete your browsing history at the end of the experiment, that is, the webpages you access will not be recorded. You can delete your browsing history yourself by pressing the button with the three-lines (三) at the topright corner of the browser.

Treatment Choice: In principle, there will be internet access during the whole duration of part 2 and you can access the internet at any point you like. The webpages you possibly access will not be recorded. The Manager can however decide to turn off the internet of the Worker who is matched with him. He does so by clicking the "Turn the internet off for the Worker"-Button that appears for Managers at the start of part 2 of the experiment. 
The Worker is then informed about the Manager's decision before he starts working on the task. The Manager himself always has internet access.

If there is internet access then note that you can also use the address line of the browser to search the internet. We will delete your browsing history at the end of the experiment, that is, the webpages you access will not be recorded. You can delete your browsing history yourself by pressing the button with the three-lines (三) at the top-right corner of the browser.

\section{Earnings in part 2}

If you are a Worker you get a wage from the Manager.

If you are the Manager, you get $1.5 \mathrm{kr}$. for each table in which you count the number of zeros correctly, and you get $1.5 \mathrm{kr}$. for each table in which the Worker matched with you counts the number of zeros correctly. A Manager earns nothing for tables that he or the Worker miscounts.

In addition, the Manager gets a fixed payment of $150 \mathrm{kr}$. The Manager offers the Worker who he is matched with a wage. He can choose between a wage of $100 \mathrm{kr}$., $150 \mathrm{kr}$., or $200 \mathrm{kr}$. The wage payment for the Worker is subtracted from the Manager's other earnings for this part.

Summary - earnings for Part 2:

Manager's earnings $=$ fixed payment of $150 \mathrm{kr}$.

$+1.5 \mathrm{kr} . \times$ number of tables that the Manager counts correctly

$+1.5 \mathrm{kr} . \times$ number of tables that the Worker counts correctly

- wage offered to the Worker (100, 150 or $200 \mathrm{kr}$.)

\section{Worker's earnings $=$ wage offered by the Manager}

Any losses a Manager might make during this part of the experiment will be deducted from his other earnings during the experiment. Note that a Manager can always exclude making losses by counting enough tables correctly. Further note that the overall earnings from the experiment can never fall below zero.

After each phase, you are informed in how many tables you counted the number of zeros correctly, and in how many you miscounted the number of zeros. Further, you are informed for how many minutes you were inactive during a phase. You are inactive if you 
need more than 2 minutes to enter the count for a table. The number of minutes that you are inactive then is calculated as the number of minutes (rounded up) you need in excess of the 2 minutes for each table.

Note that you will be informed about the earnings for this part 2 after you finished part 3. 


\section{Example}

Assume that the Manager in total (that is, in all 5 phases)

- correctly counts the number of zeros in $\mathbf{6 3}$ tables

- and miscounts the number of zeros in 3 tables.

Assume further that the Worker in total

- correctly counts the number of zeros in $\mathbf{4 9}$ tables

- and miscounts the number of zeros in 0 tables.

The Manager offers the Worker a wage of $200 \mathrm{kr}$.

Earnings:

- The Worker's earnings in part 2 is the wage of $200 \mathrm{kr}$.

- The Manger's earnings in part 2 is the fixed payment of $150+63 \times 1.5+49 \times 1.5$ $-200=118 \mathrm{kr}$.

\section{Practice questions}

Please answer the following questions:

1. Assume you are in the role of a Worker. In total,

- you correctly count the number of zeros in $\mathbf{4 1}$ tables

- and you miscount 2 tables.

In total, the Manager

- correctly counts the number of zeros in $\mathbf{1 0}$ tables

- and miscounts the number of zeros in 9 tables.

The Manager offered you a wage of $\mathbf{1 0 0} \mathrm{kr}$.

- What are your earnings in part 2?

- What are the earnings of the Manager in part 2? 
2. Assume you are in the role of a Manager. In total,

- you correctly count the number of zeros in $\mathbf{4 7}$ tables

- and you miscount 0 tables.

In total, the Worker

- correctly counts the number of zeros in $\mathbf{4 4}$ tables

- and miscounts the number of zeros in 7 tables.

You offered the Worker a wage of $150 \mathrm{kr}$.

- What are your earnings in part 2?

- What are the earnings of the Worker in part 2?

After all participants have answered the practice questions correctly, the experimenter will start the second part of the experiment. 


\section{Details for Part 3}

Treatment Internet and Choice: There will be no internet access during the remaining parts of the experiment.

\section{The task}

You are asked to state how many tables you believe the participant matched with you counted correctly in part 1 , and in part 2 , respectively.

Please press the OK-button after entering the numbers.

\section{Earnings}

Either part 1 or part 2 will be randomly drawn. If your stated number equals the true number of correctly counted tables of the participant matched with you plus-minus 1 , then your earnings in part 3 are $10 \mathrm{kr}$., otherwise they are 0. 


\section{Details for Part 4}

\section{The task}

You will now play the sending task. In this task, participants are divided into two groups: Senders and Receivers. Both the Senders and the Receivers are given $30 \mathrm{kr}$.

The Sender can choose to send 0, 10, 20 or $30 \mathrm{kr}$. to the Receiver. Any amount sent will be tripled. The Sender keeps any amount of money not send to the Receiver.

The Receiver can send back any amount up to the total amount received (that is, the amount the Sender sent multiplied by 3 ).

\section{Earnings}

The Sender's earnings in part $4=30 \mathrm{kr}$.

- any amount sent to the Receiver

+ any amount sent back by the Receiver.

\section{The Receiver's earnings in part 4 are: $=30 \mathrm{kr}$. \\ + any amount received from the Sender multiplied by three \\ - any amount sent back to the Sender.}

You will be asked to make a decision both as a Sender and as a Receiver. One of your rolls will be randomly picked. You will be matched with another randomly selected participant in the other role (hence this probably will not be the same person as in part 2 and 3). Your decision and the decision of the other player determine your earnings.

\section{Example}

You are in the role of a Sender. You have chosen to send $30 \mathrm{kr}$. to the Receiver. Hence, the Receiver could send back between 0 and $90=3 \times 30 \mathrm{kr}$. to you. The Receiver has chosen to send back $45 \mathrm{kr}$. to you.

- Your earnings in part 4 are therefore: $45 \mathrm{kr} .=30 \mathrm{kr}$ - $-30 \mathrm{kr}$. (the amount you sent) $+45 \mathrm{kr}$. (the amount received back).

- The earnings of the Receiver in part 4 are therefore: $75 \mathrm{kr} .=30 \mathrm{kr} .+90 \mathrm{kr}$. - 45 $\mathrm{kr}$. 
You are in the role of a Receiver. The Sender has chosen to send $5 \mathbf{k r}$. to you. Hence, you could send back between 0 and $15=3 \times 5 \mathrm{kr}$. to the Receiver. You have chosen to send back $3 \mathrm{kr}$. to the Sender.

- Your earnings in part 4 are therefore: $42 \mathrm{kr}$. $=30 \mathrm{kr}$. $+15 \mathrm{kr}$. (the amount you received) - $3 \mathrm{kr}$. (the amount you sent back).

- The earnings of the Sender in part 4 are therefore: $28 \mathrm{kr} .=30 \mathrm{kr} .-5 \mathrm{kr} .+3 \mathrm{kr}$.

\section{Practice exercise}

You are in the role of a Sender. You have chosen to send $7 \mathbf{k r} .^{1}$ to the Receiver. The Receiver has chosen to send back $6 \mathbf{k r}$. to you.

- Your earnings in part 4 are:

- The earnings of the Receiver in part 4 are:

You are in the role of a Receiver. The Sender has chosen to send $30 \mathrm{kr}$. to you. You have chosen to send back $2 \mathrm{kr}$. to the Sender.

- Your earnings in part 4 are:

- The earnings of the Sender in part 4 are:

\section{Details for Part 5}

\section{The task}

You are asked to fill out a survey.

\section{Payoffs}

You receive $20 \mathrm{kr}$. for filling out the survey in part 5 .

\section{End of Experiment}

At the end, your total earnings from the 5 parts, including the show up fee, is displayed on your screen. Please leave the instructions on your table. Thank you for participating in today's experiment.

\footnotetext{
${ }^{1}$ As described above the sender can only choose to send $0,10,20$ or $30 \mathrm{kr}$. No subject noticed this mistake.
} 


\section{Relevant information from consent form}

[...]

Earnings The specific earnings for the experiment will depend on your and others' decisions. The exact earnings you may receive for each part of the experiment will be specified clearly before the beginning of each part.

Aarhus University will automatically transfer the amount you earn into your NemKonto. We will start registering the payments with the administration of Aarhus University this week. Then the administrative process might take between $2-6$ weeks.

According to Danish law, Aarhus University reports payments to the tax authorities. Please note that, depending on your personal income tax rate, taxes will be deducted from the amount of money you earn in this study. That is, the amount you will receive might be lower than the pre-tax earnings stated in the experiment.

[...

Contact information Professor Alexander Koch, Department of Economics and Business, akoch@econ.au.dk. Please keep this email address in case you later have any questions regarding the payment process.

[... 